\title{
Recent advances in (chemo-)radiation therapy for rectal cancer: a comprehensive review
}

\author{
F. Roeder ${ }^{1 *} \mathbb{D}$, E. Meldolesi' ${ }^{2}$ S. Gerum ${ }^{1}$, V. Valentini ${ }^{2 \dagger}$ and C. Rödel ${ }^{3 \dagger}$
}

\begin{abstract}
The role of radiation therapy in the treatment of (colo)-rectal cancer has changed dramatically over the past decades. Introduced with the aim of reducing the high rates of local recurrences after conventional surgery, major developments in imaging, surgical technique, systemic therapy and radiation delivery have now created a much more complex environment leading to a more personalized approach. Functional aspects including reduction of acute or late treatment-related side effects, sphincter or even organ-preservation and the unsolved problem of still high distant failure rates have become more important while local recurrence rates can be kept low in the vast majority of patients. This review summarizes the actual role of radiation therapy in different subgroups of patients with rectal cancer, including the current standard approach in different subgroups as well as recent developments focusing on neoadjuvant treatment intensification and/or non-operative treatment approaches aiming at organ-preservation.
\end{abstract}

Keywords: Rectal cancer, Chemoradiation, Review

\section{Introduction and current standard approach}

Rectal cancer represents approximately one-third of all colorectal cancer with the second highest incidence and the second highest cause of cancer death in the western society [1]. Considering the restricted role of radiotherapy in the treatment of colon disease, we'll focus our review mostly on rectal cancer where radiotherapy has a leading position in combination with both surgery and chemotherapy.

During the last 3 decades, the role of radiation therapy in the management of locally advanced rectal cancers, has been gradually modified. Starting in the ' $80 \mathrm{~s}$ with a prevalent adjuvant role due to its potential in reducing pelvic recurrence after surgical resection and increasing

\footnotetext{
${ }^{*}$ Correspondence: Falk.Roeder@t-online.de

${ }^{\dagger} V$. Valentini and C. Rödel shared senior authorship

${ }^{1}$ Department of Radiotherapy and Radiation Oncology, Paracelsus

Medical University, Landeskrankenhaus, Müllner Hautpstrasse 48, 5020 Salzburg, Austria

Full list of author information is available at the end of the article
}

survival rates when combined with 5 -FU based chemotherapy [2], radiotherapy was challenged, in the early ' $90 \mathrm{~s}$, with the introduction of total mesorectal excision (TME) that significantly decreased locoregional recurrence (LRR) by itself, questioning the necessity of radiotherapy before or after surgery [3]. Several short course (5 Gy $\times 5$ days) randomized trials [4-9] have demonstrated the importance of preoperative RT plus TME in reducing LRR, in stage II and III rectal cancer patients. The assumption that adding chemotherapy to long course (45-50 Gy) preoperative radiotherapy could increase the local effect of radiotherapy, led to the comparison between radiotherapy and radiochemotherapy as neoadjuvant regimen [10]. The addition of concomitant chemotherapy to preoperative radiotherapy resulted in a significant increase in local control while only slightly increasing acute toxicity, without affecting adherence to radiotherapy, feasibility of surgery (with no increase of postoperative morbitidy), or adherence to adjuvant chemotherapy. However, no significant improvement in overall survival was observed in any single trial.

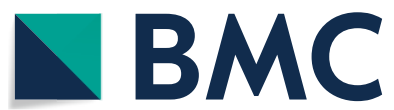

(c) The Author(s) 2020. Open Access This article is licensed under a Creative Commons Attribution 4.0 International License, which permits use, sharing, adaptation, distribution and reproduction in any medium or format, as long as you give appropriate credit to the original author(s) and the source, provide a link to the Creative Commons licence, and indicate if changes were made. The images or other third party material in this article are included in the article's Creative Commons licence, unless indicated otherwise in a credit line to the material. If material is not included in the article's Creative Commons licence and your intended use is not permitted by statutory regulation or exceeds the permitted use, you will need to obtain permission directly from the copyright holder. To view a copy of this licence, visit http://creativecommons.org/licenses/by/4.0/. The Creative Commons Public Domain Dedication waiver (http://creativeco mmons.org/publicdomain/zero/1.0/) applies to the data made available in this article, unless otherwise stated in a credit line to the data. 
Over the time, the availability of different treatment options (including radiotherapy and chemotherapy) and the possibility to use different regimens (pre- and postoperative), has resulted in an increasing demand of reliable preoperative staging. Different imaging techniques have been used to locally stage rectal cancer with variable sensitivities and specificities [11]. High-resolution MRI has been shown to be superior to clinical examination, computer tomography and endoluminal ultrasound (EUS) for rectal cancer staging [12]. The possibility to have more accurate information related to the pelvic structures as the possibility to distinguish a tumor from rectal wall, to depict the mesorectal fascia [13], to identify anatomical structures useful to support an optimal surgical technique [14] and to better characterize suspicious lymph nodes [15], made MRI the principal imaging technique in the assessment of a rectal cancer. Based on MRI imaging, able to identify poor prognostic factors preoperatively, it was possible to divide rectal cancer patients into three groups ("good", "bad" and "ugly"), according to their local and systemic failure's risks [16].

For "good" tumors, surgery alone is the mainstay of treatment. Only for tumors located in the distal rectum, radiochemotherapy can be considered with a neo-adjuvant/definitive intent to increase either sphincter preservation or achieve organ preservation by omission of surgery or a combination with local excision in selected cases.

Considering patients having "bad" MRI features, neoadjuvant treatment has been established to reduce both the risks of LLR and distant metastases. Two different regimens have been tested in those patients: conventional long-course radiochemotherapy (LCRT: 45-50 Gy with 1.8-2 Gy fractions over 5-6 weeks), mostly used in South Europe and in the United States and short-course radiotherapy (SCRT: 5 Gy $\times 5$ fractions) without preoperative chemotherapy, mostly used in the North of Europe. Several studies $[7-9,17,18]$ have investigated the two regimens in the past, even if the enrolled population was not completely comparable considering that the SCRT regimens included patients with early tumor (stage T1T2 and some resectable T3), while LCRT studies considered mainly more locally advanced rectal cancer patients (T3, T4 and unresectable tumors). Although LCRT was expected to have advantages of higher sphincter preservation and lower complication rates, several phase III randomized studies $[19,20]$ have found no difference in oncological outcomes (DFS, OS, local relapse-free survival). However, LCRT schedule showed higher pathological complete response (pCR) rate and clear resection margin. Similar results were obtained in the study of Ngan et al. [21] with a trend of better local control rate of LCRT in distal rectal lesions. Stating that there is not a real evidence to recommend one treatment modality over the other, the results of Ngan et al. justify the common practice to treat a tumor that is located in the distal rectum, close to the anal sphincter and/or locally advanced cT4 or CRM-positive tumors with a LCRT schedule.

In order to test if the longer interval between the end of radiotherapy and surgery was responsible for the higher pCR rate of the LC schedule, a SCRT regimen with delayed surgery (between 6 and 8 weeks after radiotherapy) was tested. A higher pCR rate was reported for delayed as compared with immediate surgery after SCRT [22]. Similar oncological outcomes were observed for early and delayed SCRT, with a higher acute radiation toxicity rate in the delayed and a significantly higher rate of postoperative complications in the early surgery group.

Considering the essential improvement in LC reached with the modern neoadjuvant treatments and surgical TME technique, the reduction of treatment-related sideeffects and postoperative complications is now a priority. In LCRT and SCRT with delay, a 6-8 weeks break after RT is considered standard, with a higher surgical morbidity when surgery is delayed for 11 weeks after LCRT according to a randomized trial [23], although this finding could not be confirmed in other prospective trials $[24,25]$

For the "ugly" group, characterized by a high risk for local recurrence and distant metastasis, neoadjuvant LCRT is recommended. To optimize the treatment, systemic chemotherapy can be administered either before or after neoadjuvant LCRT/SCRT, referred to as Total neoadjuvant therapy (TNT) [26].

Finally, the benefit of adjuvant chemotherapy in patients with locally advanced rectal cancer treated with neoadjuvant SCRT or LCRT is still highly controversial [27].

Although RT is accepted as an essential component of multidisciplinary treatment (MDT), specific issues still remain unaddressed. It's well defined that neoadjuvant LCRT followed by TME surgery is recommended for locally advanced rectal cancer, but what about early rectal cancer located in the lower rectum? And more, what is the role of the TNT and the chemotherapy intensification in rectal cancer? This review will recall the controversial issues and analyze the recent advances in the radiation therapy field.

\section{Neoadjuvant treatment intensification}

During the last decades, an increasing interest in intensified treatment has been paid, mainly focused on locally advanced and metastatic rectal cancer. Using the standard chemoradiation approach, only about $11-18 \%$ of patients will achieve a pathological complete remission 


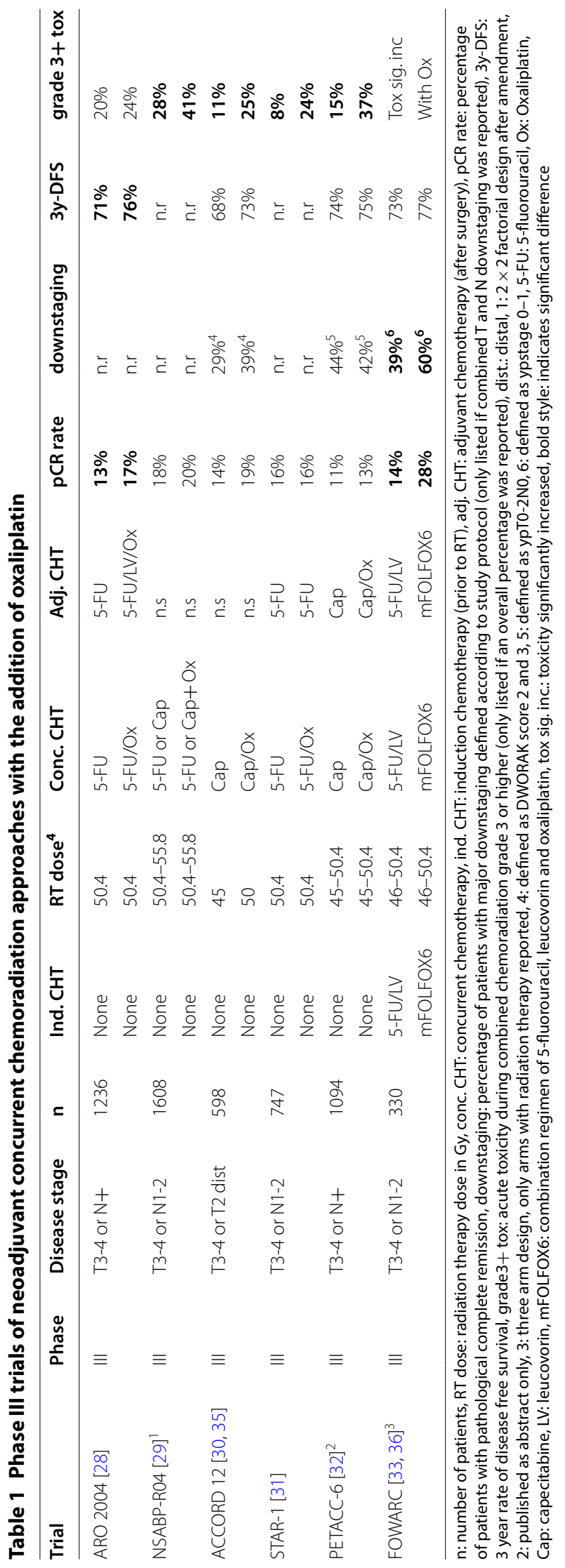


(pCR) [28-33]. Because this small group of patients shows a clearly improved overall prognosis compared to patients with less or no response [34], several strategies have been explored to improve the $\mathrm{pCR}$ rate or even omit surgery in selected cases. Those include the use of more intensive chemotherapy regimens concurrent to radiation, addition of targeting agents to concurrent chemoradiation, escalation of radiation dose or the use of altered fractionations, and the sequential use of (chemo) radiation and (intensified) induction or consolidation chemotherapy regimes in the neoadjuvant setting (total neoadjuvant therapy, TNT).

The highest level of evidence exists for adding oxaliplatin to standard 5-FU based neoadjuvant chemoradiation. Results from six phase III trials ([28-33, 35, 36], Table 1) addressing this issue have been published so far. Although two reported significantly increased pCR rates $[28,33]$ and one significantly improved diseasefree-survival (DFS) [28], all others failed to show any significant improvements in major oncological endpoints while reporting increased toxicities [29-32, 35]. Taken the slightly different treatment schedules into account, there might be a (small) benefit for the addition of (dosedense) oxaliplatin, however its efficacy does not seem to be high enough as a sole strategy. Nevertheless, adding oxaliplatin to concurrent chemoradiation might be still considered in patients with urgent need to downsizing or embedded in TNT- or non-operative management (NOM)-approaches.

Irinotecan was also tested early as an adjunct to standard 5-FU based chemoradiation based on its known activity in metastatic colorectal cancer [37]. Several phase I-II trials and one phase III trial ([38-56], Table 2) evaluating different dose schedules have reported conflicting results with pCR rates of $10-38 \%$ (weighted average $24 \%$ ). While the only phase III trial showed a significantly improved pCR rate at the cost of increased toxicity [55], the only randomized phase II trial failed to show any benefit of the addition of irinotecan to standard 5-FU based chemoradiation [51, 52]. Moreover, another randomized phase II trial comparing the addition of Irinotecan or Oxaliplatin to standard chemoradiation reported a pCR rate of only $12 \%$ with Irinotecan but $23 \%$ with Oxaliplatin with similar toxicity $[49,50]$. There is some evidence that patients with certain UGT1A1 genotypes may respond better to irinotecan-based therapies [53-55], which may allow a better patient selection in the future. Until then, the results from the ongoing British phase III ARISTOTLE trial are awaited.

Bevacizumab, a monoclonal antibody targeting vascular epithelial growth factor (VEGF), is part of most current standard first-line multidrug regimens used in metastatic colorectal cancer $[57,58]$. Therefore it has been evaluated as an adjunct to 5-FU or 5-FU/Oxaliplatin based chemoradiation in numerous phase I and II studies for rectal cancer ([59-77], Table 3). Reported pCR rates range from 8 to $40 \%$ with a weighted average of $19 \%$. The only randomized phase II trial [75] found a small but significant benefit in terms of pCR compared to standard chemoradiation with no significant increase in acute side effects or postoperative morbidity. However, several others have reported high rates of severe acute toxicities and postoperative complications mainly in terms of impaired or delayed wound healing $[64,69]$ which led to delayed or omitted adjuvant chemotherapy in a high percentage of patients. Therefore Bevacizumab does not seem to be an ideal candidate for treatment intensification at least in neoadjuvant settings outside a NOM approach.

Cetuximab, a monoclonal antibody targeting the Epidermal growth factor (EGFR), is part of the current standard multidrug regimen in metastatic KRAS wildtype colorectal cancer $[57,58]$. Therefore it (as well as other anti-EGRF antibodies like Panitumumab or downstream tyrosinkinase inhibitors like Gefitinib) has been evaluated in combination with standard 5-FU basedchemoradiation in various phase I and II trials ([78-95], Table 4) also for rectal cancer. Although most of them showed a modest toxicity profile, results in terms of pCR rates were mainly disappointing (pCR rates $0-27 \%$, weighted average 14\%). Two randomized phase II trials comparing Capecitabine- and CAPOX-based chemoradiation with or without anti-EGFR agents did not observe a significant benefit for their addition [88, 89]. Moreover, neither KRAS status nor EGFR-expression seems a robust predictor of pCR [88].

Several other agents have been tested in phase I or II trials concurrent to chemoradiation based on more or less robust preclinical and/or clinical evidence either for their activity in colorectal cancer or for enhancing radiation effects. Those include classic chemotherapy agents like Cisplatin [96], Mitomycin C [97], or Temozolomide [98], COX-2-inhibitors like Celecoxib [99-101], proteasome inhibitors like Bortezomib [102], PI3K-akt-inhibitors like Nelfinavir [103], phosphatidylserine-antibodies like Bavituximab [104], Multi-Tyrosine-Kinase-Inhibitors like Sorafenib $[105,106]$, PARP-Inhibitors like Veliparib [107] and fusion proteins like Aflibercept [108] (listed in Table 5). Reported pCR rates varied from 7 to $39 \%$. Although the addition of some agents resulted in promising $\mathrm{pCR}$ rates with acceptable toxicities, these findings should be interpreted as preliminary and further research is warranted.

Another possibility of improving chemoradiation effects is simply to increase radiation dose. Since Appelt et al. [109] provided clear evidence for a dose-response relationship between 50,4 and 70 Gy dependent on 


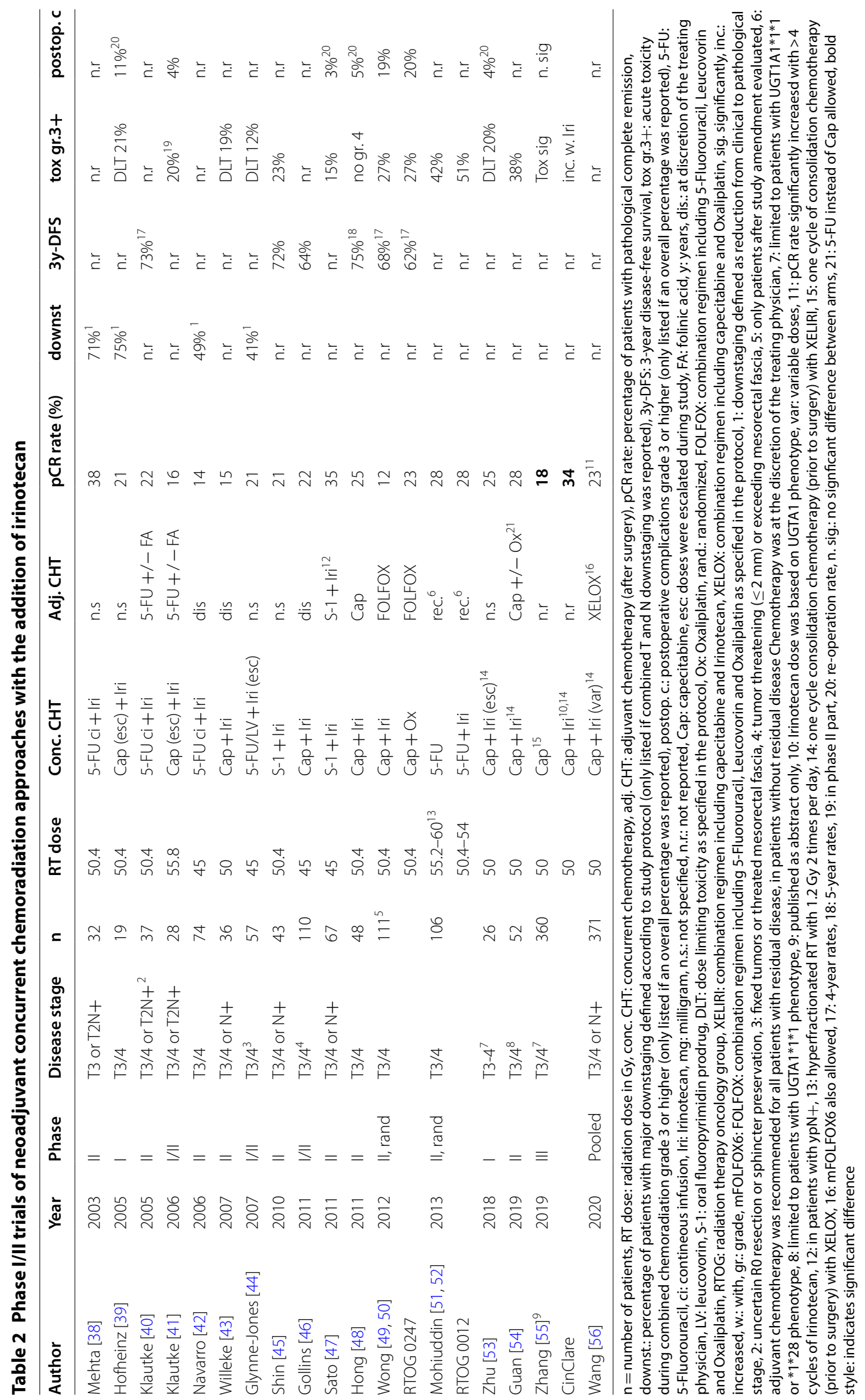




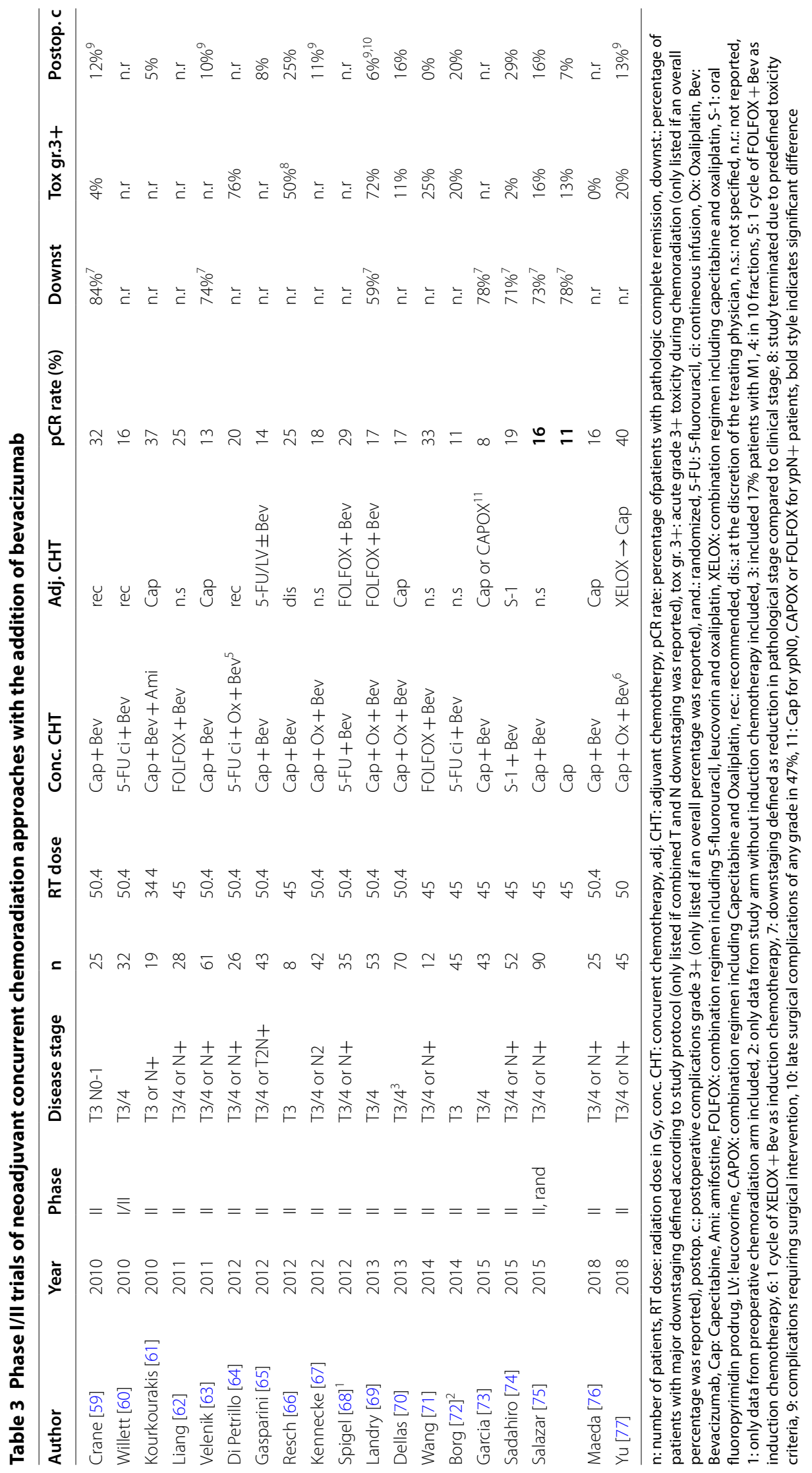




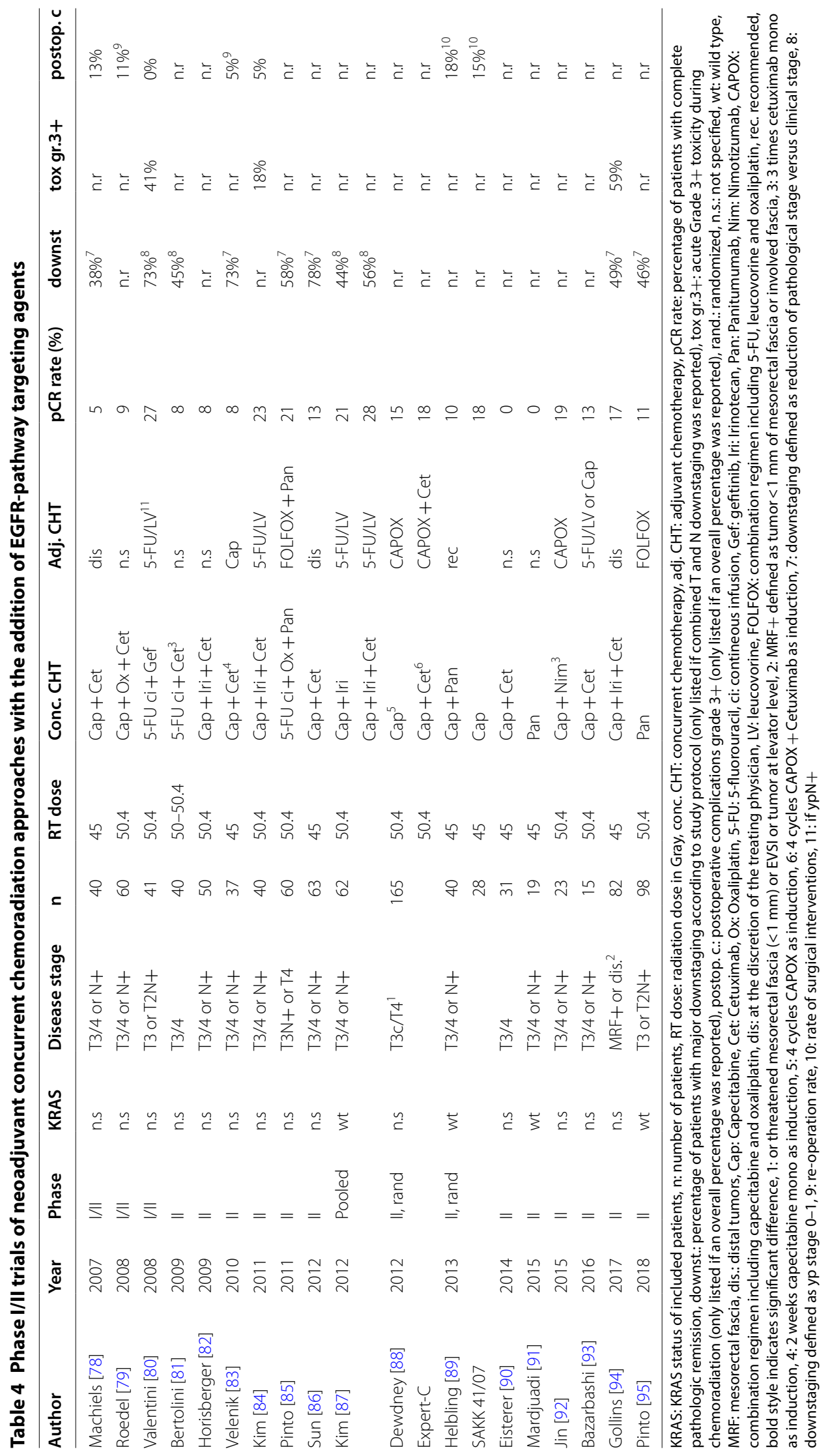




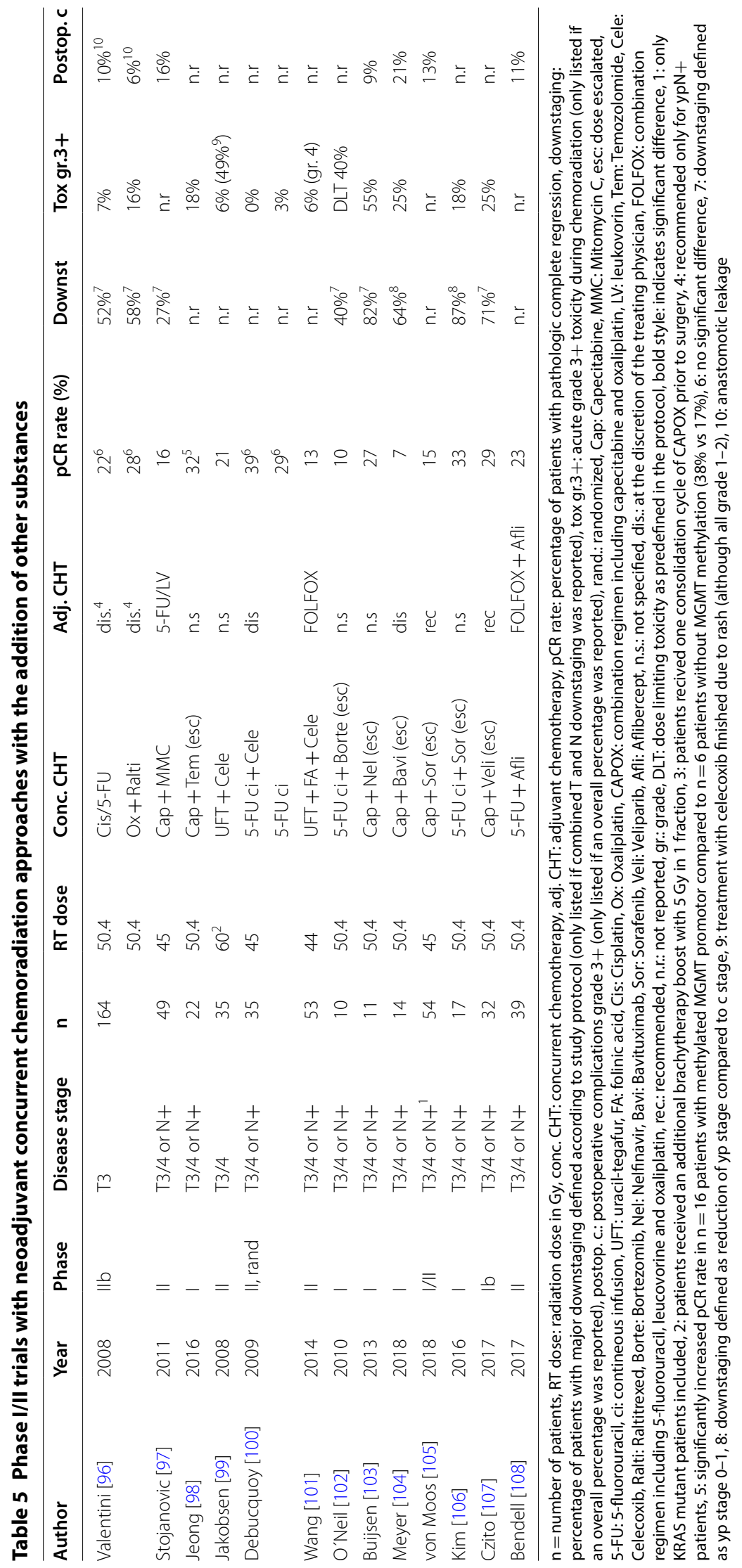


pretreatment $\mathrm{T}$ - and N-category [109], various prospective observational and phase I/II trial have evaluated dose escalation in the mentioned range within different concurrent chemotherapy regimens ([51, 52, 99, 110-142], Table 6). Dose escalation was achieved by either adding more fractions in conventional fractionation, using altered fractionation regimes or by adding a brachytherapy boost. Reported pCR rates ranged from 0 to $50 \%$ with a weighted average of $22 \%$ (excluding the population based trial [137]). Mohiuddin et al. [51, 52] reported a comparative study using conventional fractionation to either standard dose (45-50 Gy) or escalated dose (55-60 Gy) and observed a significantly increased pCR rate with dose escalation (13\% vs $44 \%$ ). Regarding brachytherapy boosts, one phase II trial with a matched cohort found a significant increase in pCR rates $(12 \%$ vs 29\%) [134] while a Danish phase III trial did not observe a significant difference in pCR rates [128]. As pCR necessitates complete remission of primary tumor and lymph nodes (with the latter usually not affected by brachytherapy), approaches using external beam techniques for dose escalation seem more meaningful. Of note, none of the mentioned trials reported excessive grade $3+$ late toxicity $(0-11 \%)$. Therefore, further evaluation of moderate radiation dose escalation in larger trials seems to be one reasonable strategy to improve $\mathrm{pCR}$ rates.

All of the mentioned strategies aimed at enhancing either the chemo- or the radiation part during concurrent chemoradiation and therefore allowed only moderate escalations due to concerns of toxicity. However, dose-intense combination chemotherapy regimens alone may result in considerable rates of downstaging and $\mathrm{pCR}$ rates as indicated by several studies [143]. Therefore, it seems reasonable to combine chemoradiation with sequential dose-intense combination chemotherapy in the neoadjuvant setting to improve pCR rates (known as TNT). Similarly to other diseases, this should result also in enhanced treatment compliance compared to adjuvant chemotherapy and further targets the unsolved problem of high distant metastases rates in rectal cancer by early initiation of systemic treatment. Several trials have already reported encouraging results using different schedules of sequential radio(chemo)therapy and combination chemotherapy ([20, 24, 25, 64, 88, 144-162], Table 7). Reported pCR rates ranged from 14 to $37 \%$ (weighted average 21\%) in the TNT arms compared to $11-25 \%$ (weighted average 14\%) in the standard chemoradiation arms of the comparative studies, indicating the superiority of the TNT approach. Moreover, the largest randomized trials observed significant benefits in terms of disease-free in the TNT arms mainly attributed to a reduction of distant failures [24,156, 160-162], although using slightly different approaches. The Timing of Rectal
Cancer Response to Chemoradiation Consortium in the United States [24, 156] performed a sequential cohort phase II study including 259 patients with T3/4 or nodal positive patients. All received upfront long-course chemoradiation (50 Gy with 5-FU c.i.) and were sequentially scheduled to receive either no or 2-6 cycles of mFOLFOX6 consolidation chemotherapy prior to surgery [24]. Chemotherapy was completed postoperatively aiming at similar total numbers of chemotherapy cycles for all four arms. The pCR rate significantly increased with the number of consolidation chemotherapy cycles from $18 \%$ (none) to $38 \%$ (6 cycles) [24]. Three-year DFS rates were also significantly increased for all TNT arms compared to the standard arm, although it has to be noted that the mean number of total chemotherapy cycles was lower in the standard arm [156]. The Polish group [157] conducted a phase III trial randomizing 515 patients with fixed T3 or T4 tumors to long-course chemoradiation (50, 4 Gy with 5-FU, leucovorin and, partly, oxalipatin) or to short-course radiation $(5 \times 5 \mathrm{~Gy})$ followed by 3 cycles of consolidation chemotherapy with FOLFOX prior to surgery [157]. They observed no significant differences in R0-resections rates (primary endpoint), $\mathrm{pCR}$ rates or DFS. The significant OS benefit at 3 years $(73 \%$ vs 65\%) [157] disappeared with longer-follow-up [20]. The RAPIDO group [160,161] used a similar approach randomizing 911 patients with high risk rectal cancer (defined as cT4, cN2, EMVI+, MRF+ or positive lateral nodes) to either long-course chemoradiation (50,4 Gy+Capecitabine) or $5 \times 5$ Gy followed by six cycles of consolidation chemotherapy with CAPOX or nine cycles of FOLFOX [160]. They found significantly improved pCR rates $(28 \%$ vs $14 \%$ ) favoring the TNT arm, which came at the cost of significantly increased acute grade $3+$ toxicity $(48 \%$ vs $25 \%)[160,161]$. Moreover, they described a significant benefit for the TNT arm in terms of disease-related treatment-failure (24\% vs 30\%) [161]. Finally, the French Group [162] tested TNT using induction chemotherapy in 461 patients with T3/T4 lesions. The patients either received long-course chemoradiation (50 Gy + Capecitabine) followed by surgery and adjuvant chemotherapy $(12 \times$ mFOLFOX6 or $8 \times$ Capox $)$ or induction chemotherapy with 6 cycles of mFOLFIRINOX followed by chemoradiation, surgery and less intensive adjuvant chemotherapy (6x mFOLFOX6 or 4x CAPOX) [162]. Similar to the RAPIDO trial, they described significantly improved pCR rates ( $28 \%$ vs $12 \%$ ) and 3-year-DFS rates (76\% vs $69 \%$ ) for the TNT arm [162].

Regarding the timing of chemoradiation and chemotherapy, both possible approaches (induction or consolidation chemotherapy) reached comparable results in terms of $\mathrm{pCR}$ rates and survival. The German $\mathrm{CAO} /$ ARO/AIO-12 trial [25], which directly compared 


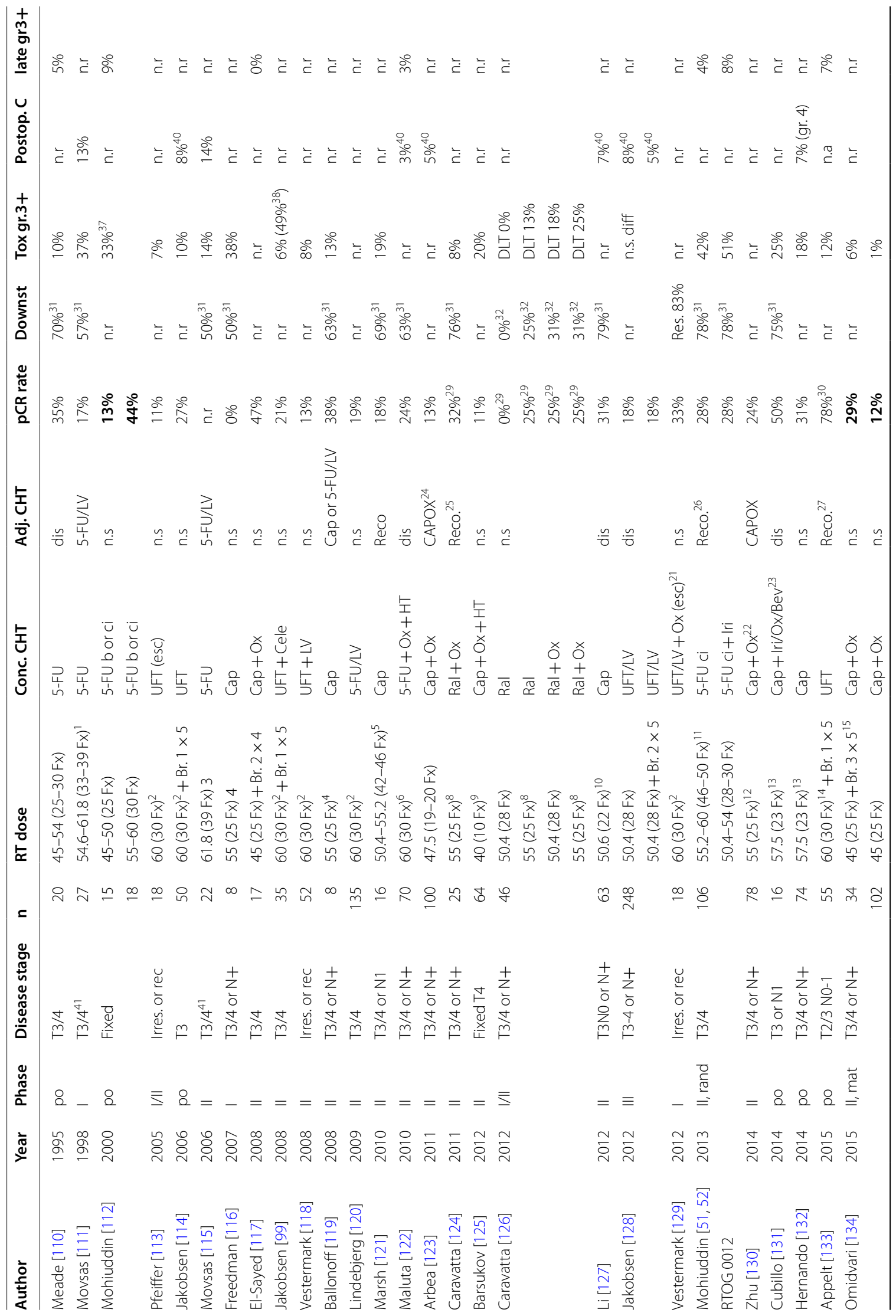




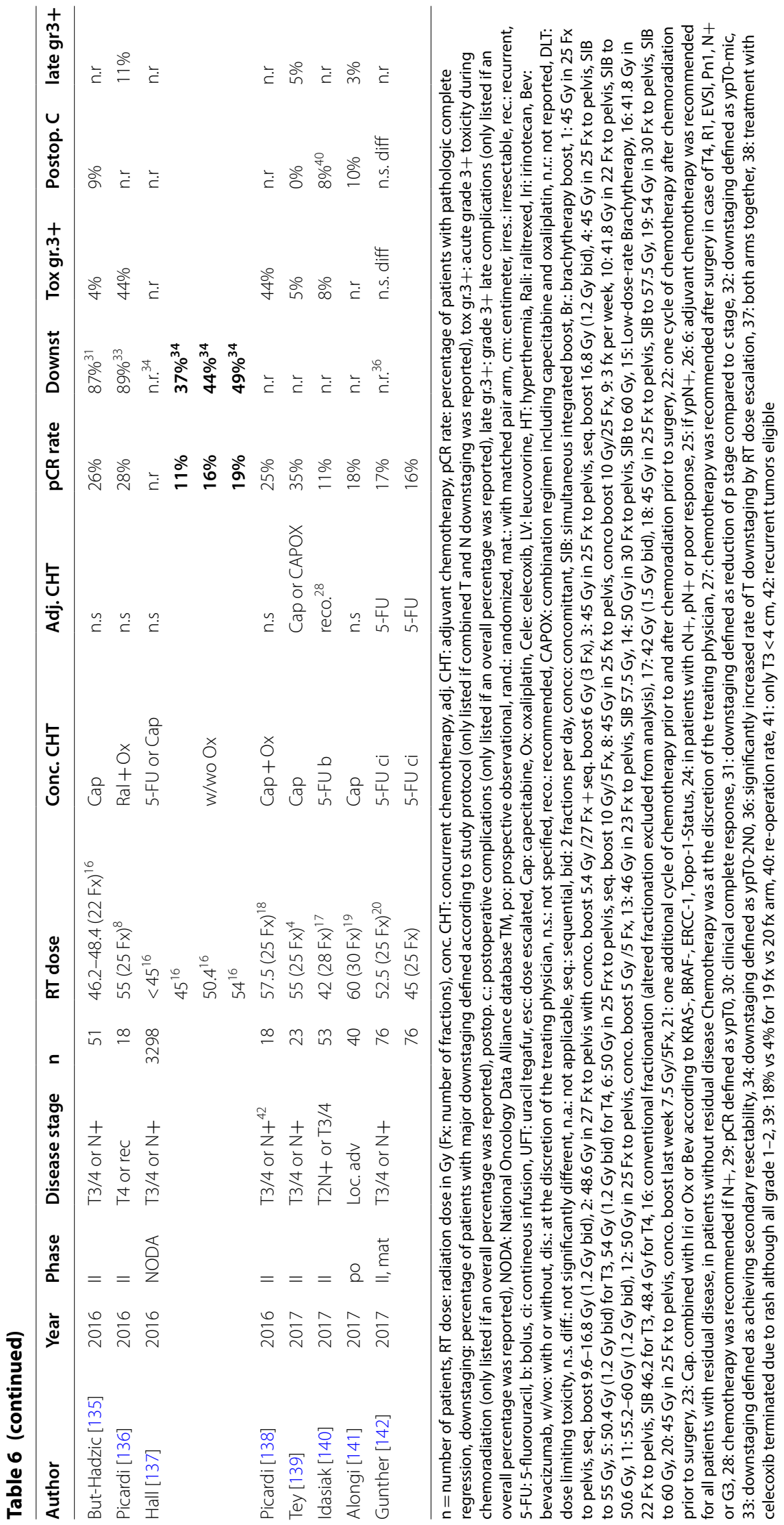




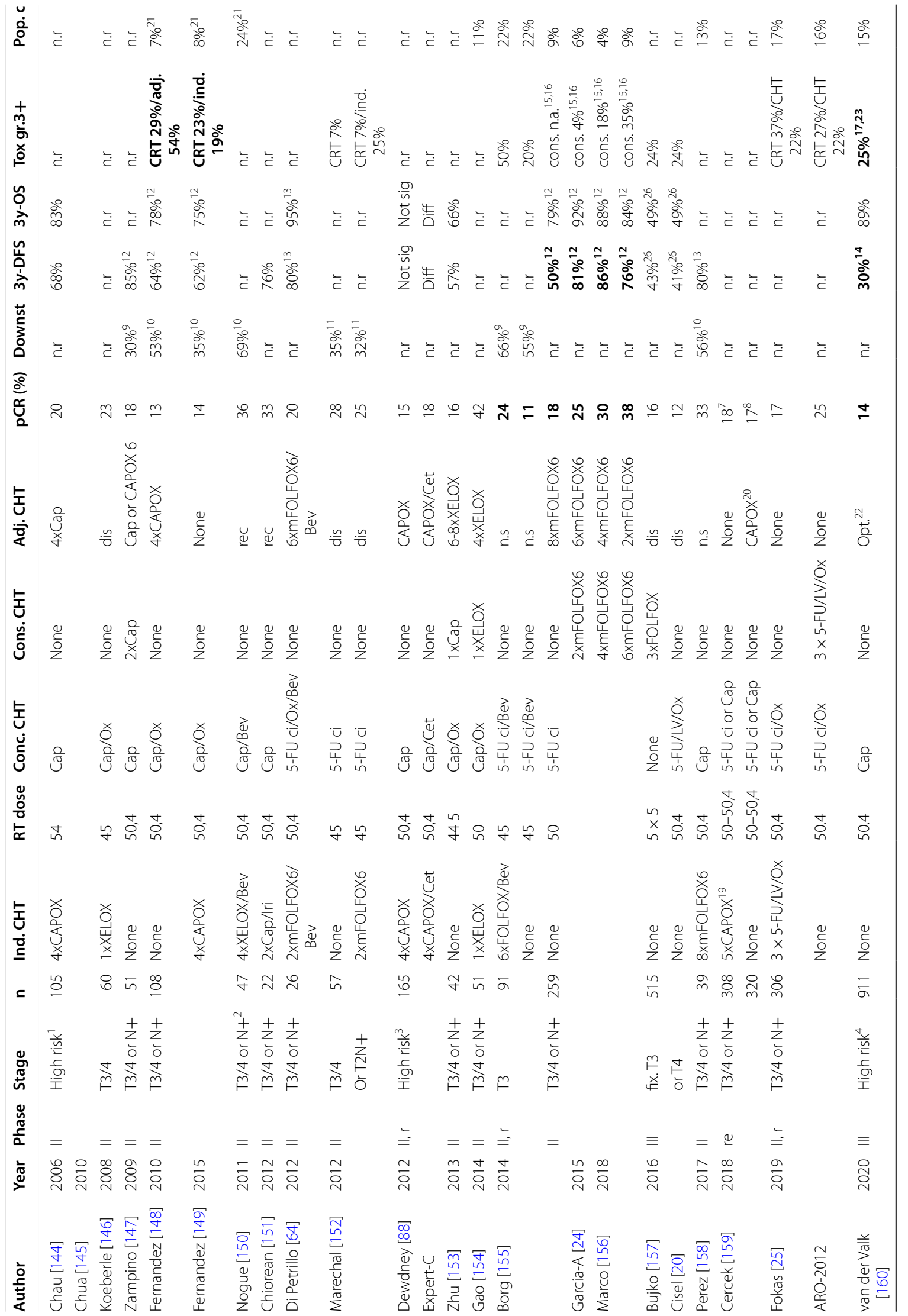




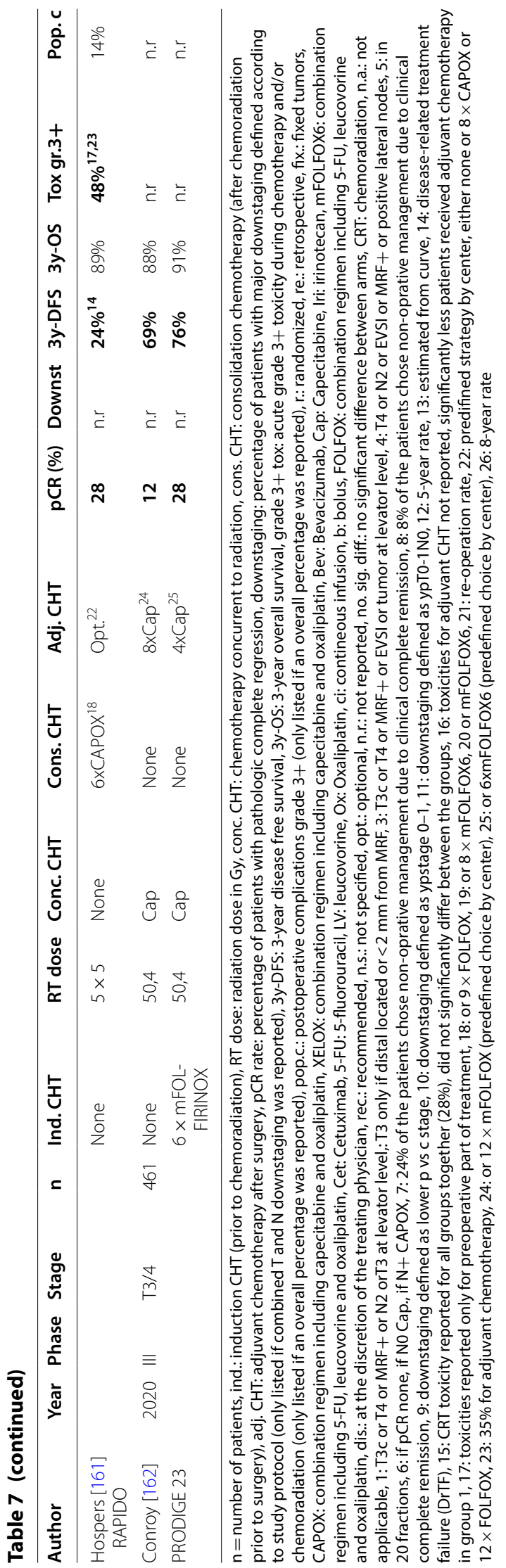


induction and consolidation chemotherapy strictly using the same schedules during chemotherapy as well as chemoradiation in both arms, and thus achieving the same time interval from treatment start to surgery, found a non-significant but distinct difference in $\mathrm{pCR}$ rates favoring the consolidation arm (17\% vs $25 \%)$. This might be explained by the longer time interval from chemoradiation to surgery, although the randomized GRECCAR-6 trial (without consolidation chemotherapy) was not able to confirm such an association [163].

In summary, several strategies to improve the $\mathrm{pCR}$ rate by neoadjuvant treatment intensification currently exist with the TNT approach probably being the most promising as it targets not only pCR rate but also seems to reduce distant failure rates with improved treatment compliance and acceptable toxicity. Although the most recent phase III trials (RAPIDO, PRODIGE 23) have been published only in abstract form so far, TNT will probably be the new standard of care for high-risk rectal cancer patients with the detailed treatment algorithm regarding to different subgroups yet to be defined.

Combination of the TNT approach with intensification of the concurrent treatment phase by moderate radiation dose escalation might be a reasonable further direction of research especially if non-operative management strategies (as addressed in the following part) are taken into account.

\section{Organ-preserving surgery and non-operative management \\ Organ-preserving surgery}

Local excision (LE, e.g. in the form of transanal endoscopic microsurgery, TEM) was initially tested as an organ preserving surgical alternative in prospective, non-randomized phase 2 studies for cT1/2 and early cT3 tumors in the lower third of the rectum after RCT with the aim of avoiding abdominoperineal resection with permanent stoma or resection with coloanal anastomosis and its morbidities while maintaining the same oncological safety. Meanwhile, results from two prospective randomized studies are available. An Italian study randomized 100 patients with distal cT2N0 tumors after neoadjuvant RCT between TEM and laparoscopic TME [164]. In both arms the R0 resection rate was $100 \%$. Conversion to radical surgery was not performed in either patient in the TEM arm. Patients operated with TEM had a significantly shortened operation time and less blood loss, but postoperative complications did not differ significantly in both groups. With a follow-up of 9.6 years there were 4 local recurrences and 2 distant metastases after TEM, 3 local recurrences and 2 distant metastases after TME. Data on quality of life, functional outcome and late morbidity were not reported.
The French GRECCAR 2 trial was a prospective, multicenter phase 3 trial that randomized patients with cT2/3 N0-1 tumors up to $8 \mathrm{~cm}$ from the anal verge and with good response (residual tumor $<2 \mathrm{~cm}$ ) 6-8 weeks after RCT into an LE versus TME group [165]. In the LE group, TME completion surgery was performed in case of ypT2-3 or R1. Of 186 patients included, $148(80 \%)$ showed good response and 145 were randomized. In the LE arm, 26/74 patients (35\%) required TME completion surgery. The primary endpoint was a combination of events: death, recurrence, surgical complication rate grade 3-4, and severe adverse events at 2 years (anal incontinence, impotence, definite colostoma). One or more of these events were observed in the intentionto-treat analysis after 2 years in $41 / 73$ patients (56\%) in the LE group and in $33 / 69$ patients $(48 \%)$ in the TME group $(p=0.43)$. There were no significant differences in the individual components of the combined endpoint between the two randomization groups, with the subgroup of patients with TME completion surgery after LE performing particularly poorly in the cumulative score of surgical complication rates and adverse events after 2 years (29\% after LE, $38 \%$ after TME, $78 \%$ after LE plus TME). With a follow-up of 60 months both treatment groups showed no significant differences in oncological 5-year endpoints (LE arm vs. TME arm: local recurrence rate $7 \%$ vs. $7 \%$, distant metastasis rate $18 \%$ vs. $19 \%$, disease-free survival $70 \%$ vs. $72 \%$, overall survival $84 \%$ vs. $82 \%)$.

Overall, the role of LE/TEM after RCT is not sufficiently clarified. Prognostically unfavorable findings after LE (R1, ypT2/3, ypN+) usually require TME completion surgery, which may be associated with significantly higher surgical complication rates, poorer long-term functional outcome and a higher rate of definitive colostomas than primary TME. Thus, the concept of neoadjuvant RCT followed by LE and possibly followed by TME completion surgery represents a potentially significant overtreatment especially for patients with early rectal cancer. Further studies will clarify which histopathological findings after LE require TME completion surgery (e.g. does every ypT2 after LE require TME?). Finally, it remains to be clarified how functional endpoints and aspects of quality of life/morbidity after RCT and LE compare to primary radical surgery.

\section{Nonoperative management following neoadjuvant standard chemoradiotherapy}

Investigators from the University of Sao Paulo were the first to pioneer the selective nonoperative management (NOM) approach for patients with potentially resectable rectal distal cancer who experience a clinically complete response (cCR) to chemoradiotherapy (CRT) [166]. In 
early reports, Habr-Gama et al. described the outcomes of 361 patients with cT2-4 and or $\mathrm{cN}+$ distal rectal cancer treated with standard neoadjuvant CRT (50.4 Gy plus 5-FU/folinic acid) and assessed for response 8 weeks after completion of CRT with clinical, endoscopic, and radiologic studies. Patients with initial cCR $(n=122,34 \%)$ underwent a strict watch-and-wait (W\&W) strategy with monthly examinations for the first year; 23 of these 112 patients $(19 \%)$ developed local tumor regrowth within 12 months. Only patients without any local regrowth within the first year of follow-up were considered to have a "sustained cCR". A total of 99 of 361 (27.4\%) patients met the criteria for sustained $\mathrm{CCR}$ and had a mean follow-up of 60 months, during which 5 patients developed endoluminal (all salvaged), 7 distant, and 1 combined recurrences [167].

Maas et al. aimed to replicate the results from Sao Paulo, evaluating also the role of modern MRI techniques in the selection and follow-up of patients [168]. Re-staging was performed 6-8 weeks after completion of standard CRT (50.4 Gy, concurrent capecitabine) for clinically T3-4 and/or N+ rectal cancer patients by use of digital rectal examination, high-resolution MRI and endoscopy plus biopsies. If these examinations indicated no residual tumor or residual fibrosis only, patients were eligible for NOM combined with intensive follow-up: 21 of the 192 (11\%) patients had evidence of cCR. With a median follow-up of 25 months, only one patient developed a local recurrence (successfully treated with salvage surgery), 20 patients are alive without disease. Patients with CCR included in a wait-and-see policy did at least as good as a control group of 20 patients with a pCR after radical surgery, but had less toxicity and better short-term bowel function. In a more recent update of this strategy, including 100 patients with cCR and a median followup of 41 months, local regrowth occurred in 15 patients (12 luminal, 3 nodal), all salvageable, with a 3-year local regrowth-free survival of $85 \%$, and a 3 year overall survival of $97 \%$. Continence after watch-and-wait based on the Vaizey incontinence score was excellent [169]. A retrospective analysis from the Netherlands with $41 \mathrm{~W} \& \mathrm{~W}$ patients who were matched with 41 patients who had undergone standard CRT and TME reports better functional results with regard to continence, defecation, micturition, and sexuality as well as a globally better quality of life in the W\&W Group [170].

Meanwhile, several population-based data collections on the W\&W strategy are available. The British "OnCoRe" project reports on 129 patients who achieved cCR following standard CRT and chose a W\&W strategy. With a median follow-up of 33 months, 44 patients (34\%) developed local regrowth, which could be treated with curative salvage surgery in 41 patients [171]. A propensity score cohort analysis showed no significant difference for DFS and OS compared to a cohort of patients matched by T-category, age and performance status. Colostomyfree survival was significantly better in the W\&W Group. The largest population-based data collection to date, the International Watch\&Wait Database (IWWD), reports on 880 patients with cCR after neoadjuvant CRT from 47 institutions and 15 countries [172]: with a median followup of 3.3 years local regrowth was of $25.2 \%$ after 2 years; $95 \%$ of these recurrences were localised in the rectal wall, and $88 \%$ were diagnosed within the first 2 years. The rate of distant metastases was low at $8 \%$, disease-specific survival and overall survival was favourable at $94 \%$ and $85 \%$ after 5 years. Systematic reviews and meta-analyses of retro- and prospective studies on the W\&W strategy describe pooled local regrowth rates of $15.7 \%$ after 2 years and $21.6 \%$ after 3 years $[173,174]$. The incidence of distant metastases is consistently low in these metaanalyses (6.8\% after 3 years in [174]).

\section{Can organ preservation by NOM be further optimized?}

Habr-Gama et al. reported the results of a more intense CRT regimen of 54 Gy in 30 fractions with 3 concurrent cycles of 5-FU/folinic acid every 21 days, followed by 3 further cycles of consolidation chemotherapy before response assessment 9 weeks after completion of CRT: initial CCR in 70 patients with T2-3 distal rectal cancer was $68 \%$, and sustained cCR at 1 year of follow-up $57 \%$ [175]. Another prospective watch-and-wait approach from Denmark evaluated patients with low-lying $(<6 \mathrm{~cm}$ from anal verge) cT2-3, cN0-1 rectal cancer [133]. Patients were treated with an increased radiation dose (60 Gy in 30 fractions with an additional 5 Gy endorectal brachytherapy boost) and concurrent oral tegafur-uracil. Response was assessed 6 weeks after CRT by endoscopy/ biopsy and MRI, and complete responders were prospectively observed. A total of 40 out of 51 eligible patients (78\%) met the criteria of cCR. With a median follow-up of 24 months, the 1- and 2-year cumulative incidence of local regrowth for these 40 patients were $15 \%$ and $26 \%$, respectively. All these patients were successfully salvaged without additional recurrences.

An emerging body of data suggests that-reminiscent to anal cancer treatment-the response to CRT in patients with rectal cancer is time-dependent, and maximal tumor regression may well take longer than the standard 6-8 weeks, especially if consolidation chemotherapy is used following CRT $[24,25]$. As mentioned above, The Timing of Rectal Cancer Response to Chemoradiation Consortium in the United States conducted a prospective phase 2 trial comparing preoperative CRT alone with CRT followed by increasing numbers of consolidation chemotherapy cycles (2-6) and thus increased 
time intervals from CRT to surgery (11, 15 and 19 weeks) [24]. The pCR rate of patients treated in study group 1 was $18 \%$ compared with $25 \%, 30 \%$, and $38 \%$, respectively, for study groups 2-4 without an apparent increase in surgical complications. Based on these results, the US organ preservation of rectal adenocarcinoma (OPRA) randomized phase 2 trial tested the feasibility of using CRT and either induction or consolidation chemotherapy for patients with MRI-staged T2-3, N0 or Tany N1-2 rectal cancer. First results, presented at ASCO 2020, showed an impressive rate of $58 \%$ organ preservation at 3 years for CRT followed by 4 months of FOLFOX/CAPOX versus $43 \%$ organ preservation for induction chemotherapy followed by CRT $(p=0.01)$ with no differences in DFS (77 versus $78 \%$, respectively) [176].

\section{Caveats of the NOM}

Despite these promising data, further prospective studies with sufficient patient numbers and follow-up are needed to better assess the risk/benefit ratio for patients who choose NOM. There have been concerns that individual patients might be disadvantaged by the omission of surgery after being diagnosed with a cCR. First, patients with initially resectable tumors might develop irresectable regrowth or lesions that require abdominoperineal resection while low anterior resection would have been sufficient in the first place. The second concern is the development of distant metastases that do no longer allow curative treatment. While patients need to be informed about the still experimental character of NOM, the current literature suggest the oncological safety of this approach. Of note, clinical examination, endoscopy and MRI to identify patients with CCR and to detect local regrowth during close follow-up require a high level of expertise and should be restricted to centers with special experience in multimodal diagnosis and therapy of rectal cancer, including NOM.

\section{Conclusion}

The role of radiation therapy and the further direction of treatment optimization have changed dramatically in the recent decade. The initial problem of high local recurrences rates after surgery, which prompted the introduction of radiation therapy into the treatment algorithm, seems to be solved for the vast majority of patients. Due to improvements in imaging and surgical technique we are now facing the contrast of evaluating the omission of radiation therapy in patients with low risk for local recurrence or the intensification of neoadjuvant (radiation therapy containing) approaches aiming at the improvement of oncological outcome in high risk patients or even attempting rates of complete remissions which allow non-operative organpreserving approaches. Several strategies for treatment intensification exist, with the TNT approach seeming the most promising option due to its improvements not only in pCR and downstaging rates, but also in reduction of distant failures without distinct increases in treatment-related toxicity compared to standard chemoradiation or SCRT with adjuvant chemotherapy. Limited (organ-preserving) surgery in patients with good response to neoadjuvant CRT seems possible in selected patients but its role needs to be clarified in further trials. Preliminary results do further suggest, that organ-preserving non-operative approaches in patients with clinical complete responses to neoadjuvant therapy are safe if proper selection and meticulous follow-up examinations are performed. Future directions may include the development of tools for a more precise identification of suitable subgroups and/or the prediction of response as well as further treatment intensification by combining TNT approaches with intensified concurrent chemoradiation approaches.

\section{Acknowledgements \\ Not applicable.}

\section{Authors' contributions}

FR and SG prepared the "Intensification of neoadjuvant treatment section" and handled the manuscript. EM and W prepared the "Introduction and current standard approach" section. CR prepared the "Organ-preserving surgery and non-operative management" section. W and CR critically reviewed the manuscript. All authors read and approved the final manuscript.

Ethics approval

Funding

The work did not receive any funding.

Availability of data and materials

Not applicable.

Ethics approval and consent to participate

Not applicable.

Consent for publication

Not applicable.

\section{Competing interests}

FR received speaker honoraria and travel grants from Intraop Medical and Lilly Germany, WV received institutional research grants from Varian Medical Systems, ViewRay Inc., Elekta, Merck-Serono and Roche. EM, SG and CR indicated no competing interests.

\section{Author details \\ ${ }^{1}$ Department of Radiotherapy and Radiation Oncology, Paracelsus Medi- cal University, Landeskrankenhaus, Müllner Hautpstrasse 48, 5020 Salzburg, Austria. ${ }^{2}$ Dipartimento di Diagnostica per Immagini, Radioterapia Oncologica ed Ematologia, UOC Radioterapia Oncologica, Fondazione Policlinico Univer- sitario "A. Gemelli" IRCCS, Roma, Italy. ${ }^{3}$ Department of Radiotherapy, University of Frankfurt, Frankfurt, Germany.}

Received: 20 August 2020 Accepted: 21 October 2020

Published online: 10 November 2020

\section{References \\ 1. Ferlay J, Colombet M, Soerjomataram I, Dyba T, Randi G, Bettio M, et al. Cancer incidence and mortality patterns in Europe: estimates for 40}


countries and 25 major cancers in 2018. Eur J Cancer. 2018;103:356-87. https://doi.org/10.1016/j.ejca.2018.07.005.

2. Hall WH. NIH consensus conference. Adjuvant therapy for patients with colon and rectal cancer. JAMA. 1990;264:1444-50. https://doi. org/10.1001/jama.264.11.1444

3. MacFarlane JK, Ryall RD, Heald RJ. Mesorectal excision for rectal cancer. Lancet (London, England). 1993;341:457-60. https://doi. org/10.1016/0140-6736(93)90207-w.

4. Kapiteijn E, Marijnen CAM, Nagtegaal ID, Putter H, Steup WH, Wiggers T, et al. Preoperative radiotherapy combined with total mesorectal excision for resectable rectal cancer. N Engl J Med. 2001;345:638-46. https ://doi.org/10.1056/NEJMoa010580.

5. Marsh PJ, James RD, Schofield PF. Adjuvant preoperative radiotherapy for locally advanced rectal carcinoma - results of a prospective, randomized trial. Dis Colon Rectum. 1994;37:1205-14. https://doi. org/10.1007/BF02257783.

6. Martling A, Holm T, Rutqvist LE, Johansson H, Moran BJ, Heald RJ, et al. Impact of a surgical training programme on rectal cancer outcomes in Stockholm. Br J Surg. 2005;92:225-9. https://doi.org/10.1002/bjs.4834.

7. Swedish Rectal Cancer Trial, Cedermark B, Dahlberg M, Glimelius B, Påhlman L, Rutqvist LE, et al. Improved survival with preoperative radiotherapy in resectable rectal cancer. N Engl J Med 1997;336:980-7. https ://doi.org/10.1056/NEJM199704033361402.

8. Sebag-Montefiore D, Stephens RJ, Steele R, Monson J, Grieve R, Khanna $\mathrm{S}$, et al. Preoperative radiotherapy versus selective postoperative chemoradiotherapy in patients with rectal cancer (MRC CRO7 and NCIC-CTG C016): a multicentre, randomised trial. Lancet. 2009;373:811-20. https:// doi.org/10.1016/S0140-6736(09)60484-0.

9. Van Gijn W, Marijnen CAM, Nagtegaal ID, Kranenbarg EMK, Putter $\mathrm{H}$, Wiggers T, et al. Preoperative radiotherapy combined with total mesorectal excision for resectable rectal cancer: 12-year follow-up of the multicentre, randomised controlled TME trial. Lancet Oncol. 2011;12:575-82. https://doi.org/10.1016/S1470-2045(11)70097-3.

10. Bosset JF, Collette L, Calais G, Mineur L, Maingon P, Radosevic-Jelic L, et al. Chemotherapy with preoperative radiotherapy in rectal cancer. $\mathrm{N}$ Engl J Med. 2006;355:1114-23. https://doi.org/10.1056/NEJMoa060829.

11. Bipat S, Glas AS, Slors FJM, Zwinderman AH, Bossuyt PMM, Stoker J. Rectal cancer: local staging and assessment of lymph node involvement with endoluminal US, CT, and MR imaging - a meta-analysis. Radiology. 2004;232:773-83. https://doi.org/10.1148/radiol.2323031368.

12. Burton S, Brown G, Daniels I, Norman A, Swift I, Abulafi M, et al. MRI identified prognostic features of tumors in distal sigmoid, rectosigmoid, and upper rectum: treatment with radiotherapy and chemotherapy. Int J Radiat Oncol Biol Phys. 2006;65:445-51. https://doi.org/10.1016/j.ijrob p.2005.12.027.

13. Brown G, Richards CJ, Newcombe RG, Dallimore NS, Radcliffe AG, Carey DP, et al. Rectal carcinoma: thin-section MR imaging for staging in 28 patients. Radiology. 1999;211:215-22. https://doi.org/10.1148/radio logy.211.1.r99ap35215.

14. Brown G, Kirkham A, Williams GT, Bourne M, Raddliffe AG, Sayman J, et al. High-resolution MRI of the anatomy important in total mesorectal excision of the rectum. Am J Roentgenol. 2004;182:431-9. https://doi. org/10.2214/ajr.182.2.1820431.

15. Beets-Tan RGH. Pretreatment MRI of lymph nodes in rectal cancer: an opinion-based review. Colorectal Dis. 2013;15:781-4. https://doi. org/10.1111/codi.12300

16. Smith N, Brown G. Preoperative staging of rectal cancer. Acta Oncol (Madr). 2008;47:20-31. https://doi.org/10.1080/02841860701697720.

17. Sauer R, Liersch T, Merkel S, Fietkau R, Hohenberger W, Hess C, et al. Preoperative versus postoperative chemoradiotherapy for locally advanced rectal cancer: results of the German CAO/ARO/AIO-94 randomized phase III trial after a median follow-up of 11 years. J Clin Oncol. 2012;30:1926-33. https://doi.org/10.1200/JCO.2011.40.1836.

18. Mullen TD, Kim EY, Apisarnthanarax S. Short-course radiation therapy versus long-course chemoradiation in the neoadjuvant treatment of locally advanced rectal cancer: new insights from randomized trials. Curr Colorectal Cancer Rep. 2017;13:165-74. https://doi.org/10.1007/ s11888-017-0359-4.

19. Bujko K, Nowacki MP, Nasierowska-Guttmejer A, Michalski W, Bebenek $M$, Kryj M. Long-term results of a randomized trial comparing preoperative short-course radiotherapy with preoperative conventionally fractionated chemoradiation for rectal cancer. Br J Surg. 2006;93:121523. https://doi.org/10.1002/bjs.5506.

20. Ciseł B, Pietrzak L, Michalski W, Wyrwicz L, Rutkowski A, Kosakowska E, et al. Long-course preoperative chemoradiation versus $5 \times 5$ Gy and consolidation chemotherapy for clinical T4 and fixed clinical T3 rectal cancer: long-term results of the randomized Polish II study. Ann Oncol. 2019:30:1298-303. https://doi.org/10.1093/annonc/mdz186.

21. Ngan SY, Burmeister B, Fisher RJ, Solomon M, Goldstein D, Joseph D, et al. Randomized trial of short-course radiotherapy versus long-course chemoradiation comparing rates of local recurrence in patients with T3 rectal cancer:Trans-Tasman Radiation Oncology Group Trial 01.04. J Clin Oncol. 2012;30:3827-33. https://doi.org/10.1200/JCO.2012.42.9597.

22. Erlandsson J, Holm T, Pettersson D, Berglund Å, Cedermark B, Radu C, et al. Optimal fractionation of preoperative radiotherapy and timing to surgery for rectal cancer (Stockholm III): a multicentre, randomised, non-blinded, phase 3, non-inferiority trial. Lancet Oncol. 2017;18:33646. https://doi.org/10.1016/S1470-2045(17)30086-4.

23. Lefevre JH, Mineur L, Kotti S, Rullier E, Rouanet P, de Chaisemartin C, et al. Effect of interval (7 or 11 weeks) between neoadjuvant radiochemotherapy and surgery on complete pathologic response in rectal cancer: a multicenter, randomized, controlled trial (GRECCAR-6). J Clin Oncol. 2016;34:3773-80. https://doi.org/10.1200/JCO.2016.67.6049.

24. Garcia-Aguilar J, Chow OS, Smith DD, et al. Effect of adding mFOLFOX6 after neoadjuvant chemoradiation in locally advanced rectal cancer: a multicenter, phase 2 trial. Lancet Oncol. 2015;16:957-66.

25. Fokas E, Allgäuer M, Polat B, et al. Randomized phase II trial of chemoradiotherapyy plus induction or consolodaation chemotherapy as total neoadjuvant therapy for locally advanced rectal cancer: CAO/ARO/AIO12. J Clin Oncol. 2019;37:3212-22.

26. Glynne-Jones R. TNT in rectal cancer may not be the new testament? EClinicalMed. 2019;16:4-5. https://doi.org/10.1016/j.eclinm.2019.10.004.

27. Bujko K, Glimelius B, Valentini V, Michalski W, Spalek M. Postoperative chemotherapy in patients with rectal cancer receiving preoperative radio(chemo)therapy: a meta-analysis of randomized trials comparing surgery \pm a fluoropyrimidine and surgery + a fluoropyrimidine \pm oxaliplatin. Eur J Surg Oncol. 2015;41:713-23. https://doi.org/10.1016/j. ejso.2015.03.233.

28. Rödel C, Graeven U, Fietkau R, et al. Oxaliplatin added to fluorouracilbased preoperative chemoradiotherapy and postoperative chemotherapy of locally advanced rectal cacer (the German CAO/ARO/AIO-04 study): final results oft eh multicentre, open-label, randomised, phase 3 trial. Lancet Oncol. 2015;16:979-89.

29 O'Connell MJ, Colangelo LH, Beart RW, et al. Capecitabine and Oxaliplatin in the preoperative multimodality treatment of rectal cancer: surgical end points from national surgical adjuvant breast and bowel projevt trial R-04. J Clin Oncol. 2014;32:1927-34.

30. Gerard JP, Azria D, Gourgou-Bourgade S, et al. Comparison of two neoadjuvant chemoradiotherapy regimens for locally advanced rectal cancer: results of the phase III trial ACCORD 12/0405-PRODIGE 2. J Clin Oncol. 2010;28:1638-44.

31. Aschele C, Cionini L, Lonardi S, et al. Primary tumor response to preoperative chemoradiation with or without oxaliplatin in locally advanced rectal cancer: pathologic results of the STAR-01 randomized phase III trial. J Clin Oncol. 2011;29:2773-80.

32. Haustermans $\mathrm{K}$, Schmoll HJ, Price T, et al. First results of the PETACC-6 randomized phase III trial in locally advanced rectal cancer. Radiother Oncol. 2014;111(suppl 1):96 ((abstract)).

33. Deng Y, Chi P, Lan P, et al. Modified FOLFOX6 with or without radiation versus fluorouracil and leucovorin with radiation in neoadjuvant treatment of locally advanced rectal cancer: initial results of the Chinese FOWARC multicentre, open-label, randomized three-arm phase III trial. J Clin Oncol. 2016;34:3300-7.

34. Maas M, Nelemans PJ, Valentini V, et al. Long term outcome in patients with a pathological complete response after chemoradiation for rectal cancer: a pooled analysis of individual patient data. Lancet Oncol. 2010;11:835-44.

35. Gerard JP, Azria D, Gourgou-Bourgade S, et al. Clinical outcome of the ACCORD 12/0405 PRODIGE 2 randomized trial in rectal cancer. J Clin Oncol. 2012;30:4558-65.

36. Deng Y, Chi P, Lan P, et al. Neoadjuvant modified FOLFOX6 with or without radiation versus fluorouracil plus radiation for locally advanced 
rectal cancer: final results of the Chinese FOWARC trial. J Clin Oncol. 2019;37:3223-33.

37. Gustavsson B, Carlsson G, Machover D, et al. A rewvies of the evolution of systemic chemotherapy in the management of colorectal cancer. Clin Colorect Cancer. 2015;14:1-10.

38. Mehta VK, Cho C, Ford JM, et al. Phase II trial of preoperative 3D conformal radiotherapy, protracted venous infusion 5-fluorouracil, and wekly CPT-11, followed by surgery for ultrasound-staged T3 rectal cancer. Int J Radiat Oncol Biol Phys. 2003;55:132-7.

39. Hofheinz RD, von Gerstenberg-Helldorf B, Wenz F, et al. Phase I trial of capecitabine and weekly irinotecan in combination with radiotherapy for neoadjuvant therapy of rectal cancer. J Clin Oncol. 2005;23:1350-7.

40. Klautke G, Feyerherd P, Ludwig K, et al. Intensified concurrent chemoradiotherapy with 5-fluorouracil and irinotecan as neoadjuvant treatment in patients with locally advanced rectal cancer. $\mathrm{Br} J$ Cancer. 2005;92:1215-20.

41. Klautke G, Küchenmeister U, Foitzik T, et al. Concurrent chemoradiation with capecitabine and weekly irinotecan as preoperative treatment for rectal cancer: results from a phase I/II study. Br J Cancer. 2006;94:976-81.

42. Navarro M, Dotor E, Rivera F, et al. A phase II study of preoperative radiotherapy and concomitant weekly irinotecan in combination with protracted venous infusion 5-fluorouracil, for resectable locally advanced rectal cancer. Int J Radiat Oncol Biol Phys. 2006;66:201-5.

43. Willeke F, Horisberger K, Kraus-Tiefenbacher U, et al. A phase II study of capecitabine and irinotecan in combination with concurrent pelvic radiotherapy (Capiri-RT) as neoadjuvant treatment of locally advanced rectal cancer. Br J Cancer. 2007;96:912-7.

44. Glynne-Jones R, Falk S, Maughan TS, et al. A phase I/II study of irinotecan when added to 5 -fluorouracil and leucovorin and pelvic radiation in locally advanced rectal cancer: a colorectal clinical oncology group study. Br J Cancer. 2007:96:551-8.

45. Shin SJ, Kim NK, Keum KC, et al. Phase II study of preoperative chemoradiotherapy (CRT) with irinotecan plus S-1 in locally advanced rectal cancer. Radiother Oncol. 2010;95:303-7.

46. Gollins S, Myint AS, Haylock B, et al. Preoperative chemoradiotherapy using concurrent capecitabine and irinotecan in magnetic resonance imaging-defined locally advanced rectal cancer: impact on long-term clinical outcomes. J Clin Oncol. 2011;29:1042-9.

47. Sato T, Ozawa H, Hatate K, et al. A phase II trial of neoadjuvant preoperative chemoradiotherapy with S-1 plus irinotecan and radiation in patients with locally advanced rectal cancer: clinical feasibility and response rate. Int J Radiat Oncol Biol Phys. 2011;79:677-83.

48. Hong YS, Kim DY, Lim SB, et al. Preoperative chemoradiation with irinotecan and capecitabine in patients with locally advanced resectable rectal cancer: long-term results of a phase II study. Int J Radiat Oncol Biol Phys. 2011;79:1171-8.

49. Wong SJ, Winter KW, Meropol NJ, et al. RTOG0247: a randomized phase II study of neoadjuvant capecitabine and irinotecan or capecitabine and oxaliplatin with concurrent radiation therapy for patients with locally advanced rectal cancer. Int J Radiat Oncol Biol Phys. 2012;82:1367-75.

50. Wong SJ, Moughan J, Meropol NJ, et al. Efficacy endpoints of RTOG 0247: a randomized phase II study of neoadjuvant radiation therapy plus concurrent capecitabine and irinotecan or capecitabine and oxaliplatin for patients with locally advanced rectal cancer. Int J Radiat Oncol Biol Phys. 2015;91:116-23.

51. Mohiuddin M, Winter K, Mitchell E, et al. Randomized phase II study of neoadjuvant combined-modality chemoradiation for distal rectal cancer: Radiation Therapy Oncology Group Trial 0012. J Clin Oncol. 2006;24:650-5.

52. Mohiuddin M, Paulus R, Mitchell E, et al. 5-year updated results of RTOG-0012 randomized phase II study of neoadjuvant combined modality chemoradiation for distal rectal cancer. Int J Radiat Oncol Biol Phys. 2013;86:523-8.

53. Zhu J, Li X, Shen Y, et al. Genotype-driven phase I study of weekly irinotecan in combination with capecitabine-based neoadjuvant chemoradiation for locally advanced rectal cancer. Radiother Oncol. 2018;129:143-8

54. Guan Y, Shen Y, Li C, et al. An expansion study of genotype-driven weekly irinotecan and capecitabine in combination with neoadjvant radiotherapy for locally advanced rectal cancer with UGT1A!*1*1 genotype. Ther Adv Gastroenterol. 2019;12:1-11.

55. Zhang Z, Sun X, Liu A, et al. A multicenter randomized phase III trial of capecitabine with or withour irinotecan driven by UGT1A1 in neoadjuvant chemoradiation of locally advanced rectal cancer (CinClare). J Clin Oncol. 2019;37(1):3510 ((abstract)).

56. Wang J, Fan J, Li C, et al. The impact of chemotherapy completion on the efficacy of irinotecan in the preoperative chemoradiatiotherapy of locally advanced rectal cancer: an expanded analysis of the CinClare phase III trial. Clin Colorectal Cancer. 2020;19:e58-69.

57. NCCN Clinical practice guidelines in Oncology-Colon Cancer, version 4.20. www.Nccn.org. 04.07.2020

58. van Cutsem E, Cervantes A, Adam R, et al. ESMO consensus guidelines for the management of patients with metastatic colorectal cancer. Ann Oncol. 2016;27:1386-422.

59. Crane $\mathrm{CH}$, Eng $\mathrm{C}$, Feig BW, et al. Phase II trial of neoadjuvant bevacizumab, capecitabine, and radiotherapy for locally advanced rectal cancer. Int J Radiat Oncol Biol Phys. 2010;76:824-30.

60. Willett CG, Duda DG, Ankukiewicz M, et al. A safety and survival analysis of neoadjuvant bevacizumab with standard chemoradiation in a phase I/II study compared with standard chemoradiation in locally advanced rectal cancer. Oncologist. 2010;15:845-51.

61. Kourkourakis MI, Giatromanolaki A, Tsoutsou P, et al. Bevacizumab, capecitabine, amifostine, and preoperative hypofractionated accelerated radiotherapy (HYPOARC) for rectal cancer: a phase II study. Int J Radiat Oncol Biol Phys. 2011;80:492-8.

62 Liang JT, Lai HS, Cheng KW. Technical feasibility of laparoscopic total mesorectal excision for patients with low rectal cancer after concurrent radiation and chemotherapy wih bevacizumab plus FOLFOX. Surg Endosc. 2011;25:305-8.

63. Velenik V, Ocvirk J, Music M, et al. Neoadjuvant capecitabine, radiotherapy, and bevacizumab (CRAB) in locally advanced rectal cancer: results of an open-label phase II study. Radiat Oncol. 2011;6:105.

64. di Petrillo T, Pricolo V, Lagares-Garcia J, et al. Neoadjuvant bevacizumab, oxaliplatin, 5-fluorouracil, and radiation for rectal cancer. Int J Radiat Oncol Biol Phys. 2012;82:124-9.

65. Gasparini G, Torino F, Ueno T, et al. A phase II study of neoadjuvant bevacizumab plus capecitabine and concomitant radiotherapy in patients with locally advanced rectal cancer. Angiogenesis. 2012;15:141-50.

66. Resch G, De Vries A, Öfner D, et al. Preoperative treatment with capecitabine, bevacizumab and radiotherapy for primary locally advanced rectal cancer-a two stage phase II clinical trial. Radiother Oncol. 2012;102:10-3.

67. Kennecke H, Berry S, Wong R, et al. Pre-operative bevacizumab, capecitabine, oxaliplatin and radiation among patiets with locally advanced or low rectal cancer: a phase II trial. Eur J Cancer. 2012;48:37-45.

68. Spigel DR, Bendell JC, McCleod M, et al. Phase Il study of bevacizumab and chemoradiation in the preoperative or adjuvant treatment of patients with stage II/III rectal cancer. Clin Colorect Cancer. 2012;11:45-52.

69. Landry JC, Feng Y, Cohen SJ, et al. Phase II study of preoperative radiation with concurrent capecitabine, oxaliplatin and bevacizumab followed by surgery and postoperative 5-FU, Leucovorine, Oxaliplatin (FOLFOX) and bevacizumab in patients with locally dvanced rectal cancer: ECOG 3204. Cancer. 2013;119:1521-7.

70. Dellas K, Höhler T, Resse T, et al. Phase II trial of preoperative radiochemotherapy with concurrent bevacizumab, capecitabine and oxaliplatin in patients with locally advanced rectal cancer. Radiat Oncol. 2013;8:90.

71. Wang CC, Liang JT, Tsai CL, et al. Neoadjuvant bevacizumab and chemoradiotherapy in locally advanced rectal cancer: early outcome and technical impact on toxicity. World J Surg Oncol. 2014;12:329.

72. Borg C, Andre T, Mantion G, et al. Pathological response and safety of two neoadjuvant strategies with bevacizumab in MRI-defined locally advanced T3 resectable rectal cancer: a randomized noncomparative phase II study. Ann Oncol. 2014a;25:2205-10.

73. Garcia M, Martinez-Villacampa M, Santos C, et al. Phase II study of preoperative bevacizumab, capecitabine and radiotherapy for resectable locally-advanced rectal cancer. BMC Cancer. 2015;15:59.

74. Sadahiro S, Suzuku T, Tanaka A, et al. Phase II study of preoperative concurrent chemoradiotherapy with S-1 plus bevacizumab for locally advanced resectable rectal adenocarcinoma. Oncology. 2015;88:49-56. 
75. Salazar R, Capdevilla J, Laquente B, et al. A randomized phase II study of capecitabine-based chemoradiation with or without bevacizumab in resectable locally advanced rectal cancer: clinical and biological features. BMC Cancer. 2015;15:60.

76 Maeda K, Shibutani M, Otani H, et al. Neoadjuvant Radiotherapy with capecitabine plus bevacizumab for locally advanced lower rectal cancer: results of a single-institute phase II study. Anticancer Res. 2018;38:4193-7.

77. Yu X, Wang QX, Xiao WW, et al. Neoadjuvant oxaliplatin and capecitabine combined with bevacizuab plus radiotherapy for locally advanced rectal cancer: results of a single-institute phase II study. Cancer Commun. 2018;38:24.

78. Machiels JP, Sempoux C, Scalliet P, et al. Phase I/II study of preoperative cetuximab, capecitabine, and external beam radiotherapy in patients wih rectal cancer. Ann Oncol. 2007;18:738-44.

79. Rödel C, Arnold D, Hipp M, et al. Phase I-II trial of cetuximab, capecitabine, oxalipaltin, and radiotherapy as preoperative treatment in rectal cancer. Int J Radiat Oncol Biol Phys. 2008;70:1081-6.

80. Valentini V, de Paoli A, Gambacorta MA, et al. Infusional 5-fluorouracil an ZD1839 (Gefitinib-Iressa) in combination with preoperative radiotherapy in patients with locally advanced rectal cancer: a phase I and II trial (1839IL/0092). Int J Radiat Oncol Biol Phys. 2008;72:644-9.

81. Bertolini F, Chiara S, Nebgala C, et al. Neoadjuvant treatment with single-agent cetuximab followed by 5-FU, cetuximab, and pelvic radiotherapy: a phase II study in locally advanced rectal cancer. Int J Radiat Oncol Biol Phys. 2009;73:466-72.

82. Horisberger K, Treschl A, Mai S, et al. Cetuximab in combination with capecitabine, irinotecan, and radiotherapy for patients with locally advanced rectal cancer: results of a phase II MARGIT trial. Int J Radiat Oncol Biol Phys. 2009;74:1487-93.

83. Velenik V, Ocvirk J, Oblak I, Anderluh F. A phase II study of cetuximab, capecitabine and radiotherapy in neoadjuvant treatment of patients with locally advanced resectable rectal cancer. Eur J Surg Oncol. 2010;36:244-50

84. Kim SY, Hong YS, Kim DY, et al. Preoperative chemoradiation with cetuXimab, irinotecan, and capecitabine in patients with locally advanced resectable rectal cancer: a multicenter phase II study. Int J Radiat Oncol Biol Phys. 2011;81:677-83.

85. Pinto C, di Fabio F, Maiello E, et al. Phase Il study of panitumumab, oxaliplatin, 5-fluorouracil, and concurrent radiotherapy as preoperative treatment in high-risk locally advanced rectal cancer patients (STARPan/ STAR-02 study). Ann Oncol. 2011;22:2424-30

86. Sun PL, Li B, Ye QF. Effect of neoadjuvant cetuximab, capecitabine, and radiotherapy for locally advanced rectal cancer: results of a phase II study. Int J Colorectal Dis. 2012;27:1325-32.

87. Kim SY, Shim EK, Yeo HY, et al. KRAS mutations status and clinical outcome of preoperative chemoradiation with cetuximab in locally advanced rectal cancer: a pooled analysis of 2 phase II trials. Int J Radiat Oncol Biol Phys. 2013;85:201-7.

88. Dewdney A, Cunningham D, Tabernero J, et al. Multicenter randomized phase II clinical trial comparing neoadjuvant oxaliplatin, capecitabine, and preoperative radiotherapy with or without cetuximab followed by total esorectal excision in patients with high-risk rectal cancer (EXPERTC). J Clin Oncol. 2012;30:1620-7.

89. Helbling D, Bodoky G, Gautschi O, et al. Neoadjuvant chemoradiotherapy with or without panitumumab in patients with wild-type KRAS, locally advanced rectal cancer (LARC): a randomized, multicenter, phase II trial SAKK 41/07. Ann Oncol. 2013;24:718-25.

90. Eisterer W, de Vries A, Öfner D, et al. Preoperative treatment with capecitabine, cetuximab, and radiotherapy for primary locally advanced rectal cancer-a phase II clinical trial. Anticancer Res. 2014;34:6767-74.

91. Mardjuadi FI, Carrasco J, Coche JC, et al. Panitumumab as a radiosensitizing agents in KRAS wild-type locally advanced rectal cancer. Targ Oncol. 2015;10:375-83.

92. Jin T, Zhu Y, Luo JL, et al. Prospective phase II trial of nimotizumab in combination with radiotherapy and concurrent capecitabine in locally advanced rectal cancer. Int J Colorectal Dis. 2015;30:337-45.

93. Bazarbashi S, Omar A, Aljubran A, et al. Pre-operative chemoradiotherapy using capecitabine and cetuximab followed by definitive surgery in patients with operable rectal cancer. Hematol Oncol Stem Cell Ther. 2016:9:147-53.
94. Gollins S, West N, Sebag-Montefiori D, et al. Preoperative chemoradiation with capecitabine, irinotecan and cetuximab in rectal cancer: significance of pre-treatment and post-resection RAS mutations. Br J Cancer. 2017;117:1286-94.

95. Pinto C, Di Bisceglie M, di Fabio F, et al. Phase Il study of preoperative treatment with external radiotherapy plus panitumumab in low-risk, locally advanced rectal cancer (RaP study/STAR-03). Oncologist. 2018;23:912-8.

96. Valentini V, Coco C, Minsky BD, et al. Randomized, multicenter, phase Illb study of preoperative chemoradiotherapy in T3 middistal rectal cancer: raltitrexed + Oxaliplatin + radiotherapy versus cisplatin + 5-fluorouracil + radiotherapy. Int J Radiat Oncol Biol Phys. 2008;70:403-12.

97. Stojanovic S, Popov I, Radosevic-Jelic L, et al. Preoperative Radiotherapy with capecitabine and mitomycin $C$ in locally advanced rectal carcinoma. Cancer Chemother Pharmacol. 2011;68:787-93.

98. Jeong JH, Hong YS, Park Y, et al. Phase 1 Study of preoperative chemoradiation therapy with temozolomide and capecitabine in patients with locally advanced rectal cancer. Int J Radiat Oncol Biol Phys. 2016;96:289-95.

99. Jakobsen A, Mortensen JP, Bisgaard, , et al. A Cox-2 inhibitor combined with chemoradiation of locally advanced rectal cancer: a phase II study. Int J Colorectal Dis. 2008;23:251-5.

100. Debucquoy A, Roels S, Goethals L, et al. Double blind randomized phase Il study with radiation +5 -fluorouracil $+/$ - celecoxib for resectable rectal cancer. Radiother Oncol. 2009;93:273-8.

101. Wang LW, Hsiao CF, Chen WT, et al. Celecoxib plus chemoradiotherapy for locally advanced rectal cancer: a phase II TCOG study. J Surg Oncol. 2014;109:580-5.

102. O'Neil BH, Raftery L, Calvo BF, et al. A phase I study of bortezomib in combination with standard 5-fluorouracil and external-beam radiation therapy for the treatment of locally advanced or metastatic rectal cancer. Clin Colorectal Cancer. 2010;9:119-25.

103. Buijsen J, Lammering G, Jansen RL, et al. Phase I trial of the combination of the Akt inhibitor nelfinavir and chemoradiation for locally advanced rectal cancer. Radiother Oncol. 2013;107:184-8.

104. Meyer J, Arriaga Y, Anandam J, et al. A phase I clinical trial of the phosphatidylserine-targeting antibody bavituximab in combination with radiation therapy and capecitabine in the preoperative treatment of rectal adenocarcinoma. Am J Clin Oncol. 2018:41:972-6.

105. von Moos R, Koeberle D, Schacher S, et al. Neoadjuvant radiotherapy combined with capecitabine and sorafenib in patients with advanced KRAS-mutated rectal cancer: a phase I/II trial (SAKK 41/08). Eur J Cancer. 2018;89:82-9.

106. Kim R, Prithviraj GK, Shridhar R, et al. Phase I study of pre-operative continuous 5-FU and sorafenib with external radiation therapy in locally advanced rectal adenocarcinoma. Radiother Oncol. 2016;118:382-6.

107. Czito BG, Deming DA, Jameson GS, et al. Safety and tolerability of veliparib combined with capecitabine plus radiotherapy in patients with locally advanced rectal cancer: a phase $1 \mathrm{~b}$ study. Lancet Gastroenterol Hepatol. 2017;2:418-26.

108. Bendell JC, Thompson D, Hemphill BM, et al. A phase 2 study of 5-fluorouracl (5-FU), Ziv-Aflibercept, and radiation for the preoperative and adjuvant treatment of patients with stage II/III rectal cancer. Cancer Invest. 2017;35:535-40.

109. Appelt AL, Ploen J, Vogelius IR, et al. Radiation doe-response model for locally advanced rectal cancer after pre-operative chemoradiotherapy. Int J Radiat Oncol Biol Phys. 2013;85:74-80.

110. Meade PG, Blatchford GJ, Thorson AG, Christensen MA, Tement CA. Preoperative chemoradiation downstages locally advanced ultrasoundstaged rectal cancer. Am J Surg. 1995;170:609-13.

111. Movsas B, Hanlon AL, Lanciano R, et al. Phase I dose escalating trial of hyperfractionated pre-operative chemoradiation for locally advanced rectal cancer. Int J Radiat Oncol Biol Phys. 1998;42:43-50.

112. Mohiuddin M, Regine WF, John WJ, et al. Preoperative chemoradiation in fixed distal rectal cancer: dose time factors for pathological complete response. Int J Radiat Oncol Biol Phys. 2000:46:883-8.

113. Pfeifer P. High-dose radiotherapy and concurrent UFT plus L-Leucovorin in locally advanced rectal cancer: a phase I trial. Acta Oncol. 2005:44:224-9. 
114. Jakobsen A, Mortensen JP, Bisgaard C, et al. Preoperative chemoradiation of locally advanced T3 rectal cancer combined with an endorectal boost. Int J Radiat Oncol Biol Phys. 2006;64:461-5.

115. Movsas B, Diratzouian H, Hanlon A, et al. Phase II trial of preoperative chemoradiation with a hyperfractionated radiation boost in locally advanced rectal cancer. Am J Clin Oncol. 2006;29:435-41.

116. Freedman GM, Meropol NJ, Sigurdson ER, et al. Phase I trial of preoperative hypofractionated intensity-modulated radiotherapy with incorporated boost and oral capecitabine in locally advanced rectal cancer. Int J Radiat Oncol Biol Phys. 2007;67:1389-93.

117. El-Sayed M, EL-Taher ZH. Prospective phase II study of brachytherapy boost as a component of neo-adjuvant chemotherapy and external beam radiation therapy in locally advanced rectal cancer. J Egypt Nat Cancer Inst. 2008:20:10-6.

118. Vestermark LW, Jacobsen A, Ovortrup C, et al. Long-term results of a phase II trial of high-dose radiotherapy (60 Gy) and UFT/L-leukocorin in patients with non-resectable locally advanced rectals cancer (LARC). Acta Oncol. 2008:47:428-33.

119. Ballonoff A, Kavanagh B, McCarter M, et al. Preoperative capecitabine and accelerated intensity-modulated radiotherapy in locally advanced rectal cancer: a phase II trial. Am J Clin Oncol. 2008;31:264-70.

120. Lindebjerg J, Spindler KL, Ploen J, Jakobsen A. The prognostic value of lymph node metastases and tumor regression grade in rectal cancer patients treated with long-course preoperative chemoradiotherapy. Colorectal Dis. 2009;11:264-9.

121. Marsh R, George TJ, Siddiqui T, et al. A phase II trial of neoadjuvant capecitabine combined with hyperfractionated accelerated radiation therapy in locally advanced rectal cancer. Am J Clin Oncol. 2010:33:251-6.

122. Maluta S, Romano M, Dall'oglio S, et al. Regional hyperthermia added to intensified preoperative chemo-radiation in locally advanced adenocarcinoma of middle and lower rectum. Int J Hyperthermia. 2010;26:108-77

123. Arbea L, Martinez-Monge R, Diaz-Gonzalez JA, et al. Four-week neoadjuvant intensity-modulated radiation therapy with concurrent capecitabine an oxaliplatin in locally advanced rectal cancer patients: a validation phase II trial. Int J Radiat Oncol Biol Phys. 2012;83:587-93.

124. Caravatta L, Padula GD, Picardi V, et al. Concomitant boost radiotherapy and multidrug chemotherapy in the neoadjuvant treatment of locally advanced rectal cancer: results of a phase II study. Acta Oncol. 2011;50:1151-7.

125. Barsukov YA, Gordeyev SS, Tkachev SI, Fedyanin MY, Perevoshikov AG. Phase II study of concomitant chemoradiotherapy with local hyperthermia and metronidazole for locally advanced fixed rectal cancer. Colorect Dis. 2013;15:1107-14.

126. Caravatta L, Picardi V, Tambaro R, et al. Neodjuvant accelerated concomitant boost radiotherapy and multidrug chemotherapy in locally advanced rectal cancer: a dose escalation study. Am J Clin Oncol. 2012;35:424-31.

127. Li JL, Ji JF, Cai Y, et al. Preoperative concomitant boost intensity-modulated radiotherapy with oral capecitabine in locally advanced mid-low rectal cancer: a phae II trial. Radiother Oncol. 2012;102:4-9.

128. Jakobsen A, Ploen J, Vuong T, et al. Dose-effect relationship in chemoradiotherapy for locally advanced rectal cancer: a randomized trial comparing two radiation doses. Int J Radiat Oncol Biol Phys. 2012;84:949-54.

129. Vestermark LW, Jensen HA, Pfeiffer P. High-dose radiotherapy (60 Gy) with oral UFT/folinic acid and escalating doses of Oxaliplatin in patients with non-resectable locally advanced rectal cancer (LARC): a phase I trial. Acta Oncol. 2012;51:311-7.

130. Zhu J, Liu F, Gu W, et al. Concomitant boost IMRT-based neoadjuvant chemoradiotherapy for clinical stage II/III rectal adenocarcinoma: results of a phase II study. Radiat Oncol. 2014;9:70.

131. Cubillo A, Hernando-Requejo O, Garcia-Garcia E, et al. A prospective pilot study of target-guided personalized chemotherapy with intensitymodulated radiotherapy in patients with early rectal cancer. Am J Clin Oncol. 2014;37:117-21.

132. Hernando-Requejo O, Lopez M, Cubillo A, et al. Complete pathological responses in locally advanced rectal cancer after preoperative IMRT and integrated-boost chemoradiation. Strahlenther Onkol. 2014:190:515-20.
133. Appelt AL, Ploen J, Harling H, et al. High-dose chemoradiotherapy and watchful waiting for distal rectal cancer: a prospective observational study. Lancet Oncol. 2015;16:919-27.

134. Omidvari S, Zohourinia S, Ansari M, et al. Efficacy and safety of lowdose-rate endorectal brachytherapy as a boost to neoadjuvant chemoradiation in the treatment of locally advanced distal rectal cancer: a phase-II clinical trial. Ann Coloproctol. 2015;31:123-30.

135. But-Hadzic J, Anderluh F, Brecelj E, et al. Acute toxicity and tumor response in locally advanced rectal cancer after preoperative chemoradiation therapy with shortening of the overall treatment time using intensity-modulated radiation therapy with simultaneous integrated Boost: a phase 2 trial. Int J Radiat Oncol Biol Phys. 2016;96:1003-10.

136. Picardi V, Deodato F, Guido A, et al. Concurrent chemoradiation with concomitant Boost in locally advanced rectal cancer: a phase II study. Anticancer Res. 2016;36:4081-8.

137. Hall MD, Schultheiss TE, Smith D, et al. Effect of increasing radiation dose on pathologic complete response in rectal cancer patients treated with neoadjuvant chemoradiation therapy. Acta Oncol. 2016;55:1392-9.

138. Picardi V, Macchia G, Guido A, et al. Preoperative chemoradiation with VMAT-SIB in rectal cancer: a phase II study. Clin Colorectal Cancer. 2016;16:16-22.

139. Tey J, Leong CN, Cheong WK, et al. A phase II trial of preoperative concurrent chemotherapy and dose escalated intensity modulated radiotherapy (IMRT) for locally advanced rectal cancer. J Cancer. 2017:8:3114-21.

140. Idasiak A, Galwas-Kliber K, Behrendt K, et al. Pre-operative hyperfractionated concurrent radiochemotherapy for locally advanced rectal cancers: a phase II clinical study. Br J Radiol. 2017;90:20160731.

141. Alongi F, Fersino S, Mazzola R, et al. Radiation dose intensification in pre-operative chemo-radiotherapy for locally advanced rectal cancer. Clin Transl Oncol. 2017;19:189-96.

142. Gunther JR, Chadha AS, Shin US, et al. Preoperative radiation dose escalation for rectal cancer using a concomitant boost strategy improves tumor downstaging without increasing toxicity: a matched-pair analysis. Adv Radiat Oncol. 2017:2:455-64.

143. Jalil O, Claydon L. Arulampam. Review of neoadjuvant chemotherapy alone in locally advanced rectal cancer. J Gastrointest Cancer. 2015:46:219-36.

144. Chau I, Bown G, Cunningham D, et al. Neoadjuvant Capecitabine and Oxaliplatin followed by synchronous chemoradiation and total mesorectal excision in magnetic-resonance imaging-defined poor-risk rectal cancer. J Clin Oncol. 2006;24:668-74.

145. Chua YJ, Barbachano Y, Cunningham D, et al. Neoadjuvant capecitabine and Oxaliplatin before chemoradiotherapy and total mesorectal excision in MRI-defined poor-risk rectal cancer: a phase 2 trial. Lancet Oncol. 2010;11:241-8.

146. Koeberle D, Burkhard R, von Moos R, et al. Phase II study of capecitabine and Oxaliplatin given prior to and concurrently with preoperative pelvic radiotherapy in patients with locally advanced rectal cancer. $\mathrm{Br}$ J Cancer. 2008;98:1204-9.

147. Zampino MG, Magni E, Leonardi MC, et al. Capecitabine initially concomitant to radiotherapy the preoperatively administered in locally advanced rectal cancer. Int J Radiat Oncol Biol Phys. 2009:75:421-7.

148. Fernandez-Martos C, Pericay C, Aparicio J, et al. Phase II, randomized study of concomitant chemoradiotherapy followed by surgery and adjuvant capitabine and Oxaliplatin (CAPOX) compared with induction CAPOX followed by concomitant chemoradiotherapy and surgery in magnetic resonance imaging-defined, locally advanced rectal cancer: Grupo cancer de Recto 3 study. J Clin Oncol. 2020;28:859-65.

149. Fernandez-Martos C, Garcia-Albeniz X, Pericay C, et al. Chemoradiation, surgery and adjuvant chemotherapy versus induction chemotherapy followed by chemoradiation and surgery: long-term results of the Spanish GCR-3 phase II randomized trial. Ann Oncol. 2015;26:1722-8.

150. Nogue M, Salud A, Vicente $P$, et al. Addition of bevacizumab to XELOX induction therapy plus concomitant capecitabine-based chemoradiotherapy in magnetic resonance imaging-defined poor-prognosis locally advanced rectal cancer: the AVACROSS study. Oncologist. 2011:16:614-20.

151. Chiorean EG, Sanghani S, Schiel MA, et al. Phase II and gene expression analysis trial of neoadjuvant capecitabine plus irinotecan followed by capicitabine-based chemoradiotherapy for locally advanced rectal 
cancer: Hoosier Oncology Group Gl03-53. Cancer Chemother Pharmacol. 2012;70:25-32.

152. Marechal R, Vos B, Polus M, et al. Short course chemotherapy followed by concomitant chemoradiotherapy and surgery in locally advanced rectal cancer: a randomized multicentric phase II study. Ann Oncol. 2012;23:1525-30.

153. Zhu J, Gu W, Lian P, et al. A phase II trial of neoadjuvant IMRT-based chemoradiotherapy followed by one cycle of capecitabine for stage II/ III rectal adenocarcinoma. Radiat Oncol. 2013:8:130.

154. Gao YH, Lin JZ, An X, et al. Neoadjuvant sandwich treatment with Oxaliplatin and capecitabine administered prior to, concurrently with, and following radiation therapy in locally advanced rectal cancer: a prospective phase II trial. Int J Radiat Oncol Biol Phys. 2014;90:1153-60.

155. Borg C, Andre T, Mantion G, et al. Pathological response and safety of two neoadjuvant strategies with bevacizumab in MRI-defined locally advanced $T 3$ resectable rectal cancer: a randomized noncomparative phase II study. Ann Oncol. 2014b;25:2205-10.

156. Marco MR, Zhou L, Patil S, et al. Consolidation mFOLFOX6 chemotherapy after chemoradiotherapy improves survival in patients with locally advanced rectal cancer: final results of a multicenter phase II trial. Dis Col Rect. 2018;61:1146-55.

157. Bujko K, Wyrwicz L, Rutkowski A, et al. Long-course Oxaliplatin-based preoperative chemoradiation versus $5 \times 5$ Gy and consolidation chemotherapy fpr CT4 or fixed CT3 rectal cancer: results of a randomized phase III study. Ann Oncol. 2016;27:834-42.

158. Perez K, Safran H, Sikov W, et al. Complete neoadjuvant treatment for rectal cancer: The Bronw university oncology group CONTRE study. Am J Clin Oncol. 2017:40:282-7.

159 Cercek A, Campbell SD, Strombom P, et al. Adoption of total neoadjuvant therapy for locally advanced rectal cancer. JAMA Oncol. 2018;4:e180071.

160. van der Valk MJ, Marijnen CA, van Etten B, et al. Compliance and tolerability of short-course radiotherapy followed by preoperative chemotherapy and surgery for high.risk rectal cancer-results of the international randomized RAPIDO-trial. Radiother Oncol. 2020;147:75-83.

161 Hospers G, Bahadoer RR, Dijkstra EA, et al. Short course radiotherapy followed by chemotherapy before TME in locally advanced rectal cancer: the randomized RAPIDO trial (abstract). J Clin Oncol. 2020;38(suppl):4006.

162 Conroy T, Lamfichekh N, Etienne PL, et al. Total neoadjuvant therapy with $\mathrm{mFOLFIRINOX}$ versus preoperative chemoradiation in patiets with locally advanced rectal cancer: final results of PRODIGE 23 phase III trial, a UNICANCER GI trial (abstract). J Clin Oncl. 2020;38(suppl):4007.

163. Lefevre J, Mineur L, Cachanado M, et al. Does a longer waiting period after neoadjuvant radio-chemotherapy improve the oncological prognosis of rectal cancer? Three years' results of the GRECCAR-6 randomized multicenter trial. Ann Surg. 2019;270(747):753.

164. Lezoche $\mathrm{E}$, Baldarelli M, Lezoche $\mathrm{G}$, et al. Randomized clinical trial of endoluminal locoregional resection versus laparoscopic total mesorectal excision for T2 rectal cancer after neoadjuvant therapy. Br J Surg. 2012;99:1211-8

165. Rullier E, Vendrely V, Asselineau J, et al. (2020) Organ preservation with chemoradiotherapy plus local excision for rectal cancer: 5 -year results of the GRECCAR 2 randomised trial. Lancet Gastroenterol Hepatol. 2020:5:465-74.
166. Habr-Gama A, Perez RO, Nadalin W, Sabbaga J, Ribeiro U Jr, Silva e Sousa AH Jr, Campos FG, Kiss DR, Gama-Rodrigues J. Operative versus nonoperative treatment for stage 0 distal rectal cancer following chemoradiation therapy: long-term results. Ann Surg. 2004;240(4):711-7.

167. Habr-Gama A, Perez RO, Proscurshim I, et al. Patterns of failure and survival for nonoperative treatment of stage $c 0$ distal rectal cancer following neoadjuvant chemoradiation therapy. J Gastrointest Surg. 2006;10:1319-28.

168. Maas M, Beets-Tan RG, Lambregts DM, Lammering G, Nelemans PJ, Engelen SM, van Dam RM, Jansen RL, Sosef M, Leijtens JW, Hulsewé KW, Buijsen J, Beets GL. Wait-and-see policy for clinical complete responders after chemoradiation for rectal cancer. J Clin Oncol. 2011;29(5):4633-40.

169. Martens MH, Maas M, Heijnen LA, Lambregts DM, Leijtens JW, Stassen LP, Breukink SO, Hoff C, Belgers EJ, Melenhorst J, Jansen R, Buijsen J, Hoofwijk TG, Beets-Tan RG, Beets GL. Long-term outcome of an organ preservation program after neoadjuvant treatment for rectal cancer. J Natl Cancer Inst. 2016;108(12):djw171.

170. Hupkens BJP, Martens MH, Stoot JH, Berbee M, Melenhorst J, Beets-Tan RG, Beets GL, Breukink SO. Quality of life in rectal cancer patients after chemoradiation: watch-and-wait policy versus standard resection-a matched-controlled study. Dis Colon Rectum. 2017;60(10):1032-40.

171. Renehan AG, Malcomson L, Emsley R, Gollins S, Maw A, Myint AS, Rooney PS, Susnerwala S, Blower A, Saunders MP, Wilson MS, Scott N, O'Dwyer ST. Watch-and-wait approach versus surgical resection after chemoradiotherapy for patients with rectal cancer (the OnCoRe project): a propensity-score matched cohort analysis. Lancet Oncol. 2016;17(2):174-83.

172. van der Valk MJM, Hilling DE, Bastiaannet E, Meershoek-Klein Kranenbarg E, Beets GL, Figueiredo NL, Habr-Gama A, Perez RO, Renehan AG, van de Velde $\mathrm{CJH}$; IWWD Consortium. Long-term outcomes of clinical complete responders after neoadjuvant treatment for rectal cancer in the International Watch \& Wait Database (IWWD): an international multicentre registry study. Lancet. 2018:391(10139):2537-45.

173. Dattani M, Heald RJ, Goussous G, Broadhurst J, São Julião GP, HabrGama A, Perez RO, Moran BJ. Oncological and survival outcomes in watch and wait patients with a clinical complete response after neoadjuvant chemoradiotherapy for rectal cancer: a systematic review and pooled analysis. Ann Surg. 2018;268(6):955-67.

174. Dossa F, Chesney TR, Acuna SA, Baxter NN. A watch-and-wait approach for locally advanced rectal cancer after a clinical complete response following neoadjuvant chemoradiation: a systematic review and metaanalysis. Lancet Gastroenterol Hepatol. 2017;2(7):501-13.

175. Habr-Gama A, Sabbaga J, Gama-Rodrigues J, et al. Watch and wait approach following extended neoadjuvant chemoradiation for distal rectal cancer: are we getting closer to anal cancer management? Dis Colon Rectum. 2013:56:1109-17.

176. Garcia-Aguilar J, Patil S, Kim JK, et al. Preliminary results of the organ preservation of rectal adenocarcinoma (OPRA) trial. https://meetinglib rary.asco.org/record/187194/abstract. Accessed 1 July 2020.

\section{Publisher's Note}

Springer Nature remains neutral with regard to jurisdictional claims in published maps and institutional affiliations.

\footnotetext{
Ready to submit your research? Choose BMC and benefit from:

- fast, convenient online submission

- thorough peer review by experienced researchers in your field

- rapid publication on acceptance

- support for research data, including large and complex data types

- gold Open Access which fosters wider collaboration and increased citations

- maximum visibility for your research: over $100 \mathrm{M}$ website views per year
}

At BMC, research is always in progress.

Learn more biomedcentral.com/submissions 